PREPARED FOR THE U.S. DEPARTMENT OF ENERGY, UNDER CONTRACT DE-AC02-76-CHO-3073

PPPL-2804

UC-427

\title{
A POST-PROCESSOR FOR THE PEST CODE
}

BY

S. PRIESCHE, J. MANICKAM, AND J.L. JOHNSON

January 1992

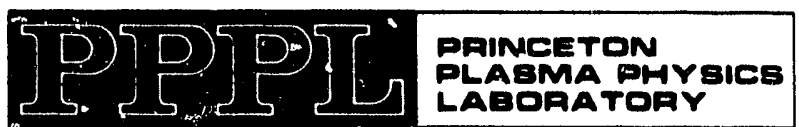

\section{plazma mhy Bice}

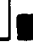

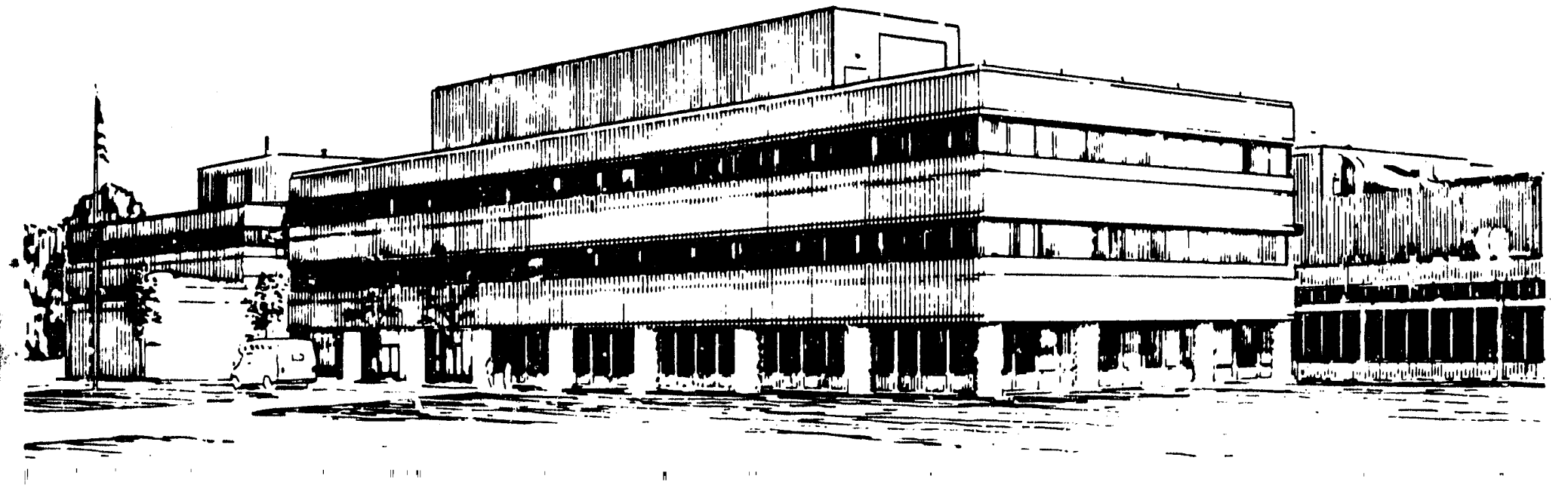




\section{NOTICE}

This report was prepared as an account of work sponsored by an agency of the United States Government. Neither the United States Government nor any agency thereof, nor any of their employees, makes any warranty, express or implied, or assumes any legal liability or responsibility for the accuracy, completeness, or usefulness of any information, apparatus, product, or process disclosed, or represents that its use would not infringe privately owned rights. Reference herein to any specific commercial produce, process, or service by trade name, trademark, manufacturer, or otherwise, does not necessarily constitute or imply its endorsement, recommendation, or favoring by the United States Government or any agency thereof. The views and opinions of authors expressed herein do not necessarily state or reflect those of the United States Government or any agency thereof.

\section{NOTICE}

This report has been reproduced directly from the best available copy.

Available to DOE and DOE contractors from the:

Office of Scientific and Technical Information

P.O. Box 62

Oak Ridge, TN 37831 ;

Prices available from (615) 576-8401.

Available to the public from the:

National Technical Information Service

U.S. Department of Commerce

5285 Pont Royal Road

Springfield, Virginia 22161

$703-487-4650$ 


\title{
A Post-Processor for the PEST Code
}

\author{
S. Preische, J. Manickam, and J. L. Johnson \\ Princeton Plasma Physics Laboratory \\ Princeton University
}

\begin{abstract}
A new post-processor has been developed for use with output from the PEST tokamak stability code. It allows us to use quantities calculated by PEST and take better advantage of the physical picture of the plasma instability which they can provide. This will improve comparison with experimentally measured quantities as well as facilitate understanding of theoretical studies.
\end{abstract}




\section{Introduction}

The PEST code[1] is used to determine the linear ideal MHD stability of axisymmetric tokamak configurations. It is a variational code which determines the set, of displacement vectors $\boldsymbol{\xi}$ which minimizes the Lagrangian, $\delta W-\omega^{2} K$, where $\delta W$ and $K$ are the potential and kinetic energies associated with perturbations from a given equilibrium. The PEST code is used for a variety of purposes including tokamak machine design, the determination of $\beta$ limits and their dependence on current and pressure profiles, and study of the physics of instabilities, for example, by analysis of the mode structure. We are concentrating here on the latter use.

The mode structure of the perturbed quantities gives us some clues into the physical origin of the instability. The PEST code has not fully exploited this capability. In fact, even the usual plots of the Fourier components of $\xi_{\psi}$ are misleading since they do not include the proper normalizations. To remedy this deficiency, and enhance the capabilities of the code, we have constructed a post-processor. The new code is able to:

a) construct properly normalized components of the eigenfunction $\boldsymbol{\xi}$ in order to see the true relative amplitudes of the various modes,

b) look at the eigenfunction in an orthogonal basis, as opposed to PEST's nonorthogonal basis, as an orthogonal basis may be easier to work with for some analyses,

c) compute and display quantities which can be measured experimentally, e.g., components of the perturbed magnetic field $\boldsymbol{Q}$, in order to compare a known mode structure from PEST with experimental measurements, and

d) test the degree of compressibility for a specific eigenvalue by evaluating $\boldsymbol{\nabla} \cdot \boldsymbol{\xi}$.

\section{Formulation}

\subsection{PEST representation of $\xi$}

For a given tokamak plasma equilibrium, with

$$
\boldsymbol{B}=[f(\psi) \nabla \phi \times \nabla \psi+R g(\psi) \nabla \phi],
$$

$$
\mathcal{J}=(\nabla \psi \times \nabla \theta \cdot \nabla \phi)^{-1}
$$


where $\mathcal{J}$ is the Jacobian, $R$ is the major radius of the plasma, and $\psi$ is a normalized poloidal flux, the PEST code determines $\xi_{\psi}^{P}, \xi_{s}^{P}, \xi_{B}^{P}$, where the displacement vector $\boldsymbol{\xi}$ for perturbations about the equilibrium is

$$
\boldsymbol{\xi}=\frac{\mathcal{J} \xi_{\psi}^{P}}{g R^{2}} \nabla \theta \times B+\frac{i \mathcal{J} \xi_{S}^{P}}{g R^{2}} B \times \nabla \psi+i \xi_{B}^{P} B .
$$

Each component, $\alpha$, of $\boldsymbol{\xi}$ has been decomposed such that

$$
\xi_{\alpha}^{P}=\sum_{m, n} \xi_{\alpha, m n}^{P}(\psi) e^{i(m \theta-n \phi)}
$$

Since axisymmetry is assumed, the Fourier coefficients for different values of $n$ decouple and each toroidal mode number can be examined separately. However, the magnitudes of the PEST coordinates $\nabla \psi, \nabla \theta, \nabla \phi$, and the Jacobian, $\mathcal{J}=v X^{2} / 2 \pi R$ [with $X$ the distance from the major axis to the point $(\psi, \theta)$ ], have $\theta$ dependencies so that graphs of these Fourier coefficients, $\xi_{\alpha, m n}^{P}$, without the appropriate normalization do not descibe the physical eigenfunctions.

\subsection{Normalized components of $\xi$}

To get a better physical picture of the Fourier modes of the displacement vector, we define a set of unit vectors,

$$
\mathbf{e}_{\psi} \equiv \frac{\nabla \theta \times B}{|\nabla \theta \times B|}, \quad \mathbf{e}_{s} \equiv \frac{B \times \nabla \psi}{B|\nabla \psi|}, \quad \mathbf{e}_{b} \equiv \frac{B}{B},
$$

write

$$
\begin{aligned}
\boldsymbol{\xi}= & \xi_{\psi} \mathbf{e}_{\psi}+\xi_{s} \mathbf{e}_{s}+\xi_{B} \mathbf{e}_{b} \\
= & \frac{v X}{2 \pi g R^{3}}\left[R^{2} g^{2}|\nabla \theta|^{2}+f^{2}(\nabla \psi \cdot \nabla \theta)^{2}\right]^{1 / 2} \xi_{\psi}^{P} \mathbf{e}_{\psi} \\
& +i \frac{v X|\nabla \psi|}{2 \pi g R^{3}}\left[R^{2} g^{2}+f^{2}|\nabla \psi|^{2}\right]^{1 / 2} \xi_{s}^{P} \mathbf{e}_{s} \\
& +\frac{i}{X}\left[R^{2} g^{2}+f^{2}|\nabla \psi|^{2}\right]^{1 / 2} \xi_{B}^{P} \mathbf{e}_{b}
\end{aligned}
$$

and Fourier decompose $\xi_{\psi}, \xi_{s}, \xi_{B}$ in $\theta$. This set of Fourier coefficients is properly normalized and comparision of the relative amplitudes is meaningful. 


\subsection{Orthogonal projection of $\xi$}

Since the PEST basis vectors are not orthogonal, i.e., $\nabla \psi \cdot \nabla \theta \neq 0$, it is useful to look at $\boldsymbol{\xi}$ in an orthogonal system. To do this we define a new set of orthogonal unit vectors:

$$
\mathbf{e}_{r} \equiv \frac{\nabla \psi}{|\nabla \psi|}, \quad \mathbf{e}_{\theta} \equiv \frac{B \times \nabla \psi}{B|\nabla \psi|}, \quad \mathbf{e}_{b} \equiv \frac{\boldsymbol{B}}{B} .
$$

Then we can write:

$$
\begin{aligned}
\boldsymbol{\xi}= & \xi_{r} \mathbf{e}_{r}+\xi_{\theta} \mathbf{e}_{\theta}+\xi_{B} \mathbf{e}_{b} \\
= & \frac{\xi_{\psi}^{P}}{R \mid \nabla \psi} \mathbf{e}_{r} \\
& +\frac{v \cdot X|\nabla \psi|}{2 \pi g R^{3}}\left[R^{2} g^{2}+f^{2}|\nabla \psi|^{2}\right]^{1 / 2}\left(i \xi_{s}^{P}-\frac{(\boldsymbol{\nabla} \psi \cdot \nabla \theta) \xi_{\psi}^{P}}{|\nabla \psi|^{2}}\right) \mathbf{e}_{\theta} \\
& +\frac{i}{X}\left[R^{2} g^{2}+f^{2}|\nabla \psi|^{2}\right]^{1 / 2} \xi_{B}^{P} \mathbf{e}_{b} .
\end{aligned}
$$

This form is useful for looking at radial displacements, as $\mathbf{e}_{\boldsymbol{r}}$ is always perpendicular to a flux surface and in a toroidal cross section, whereas $\mathbf{e}_{\psi}$ has components in all three coordinate directions, because

$$
\boldsymbol{\nabla} \theta \times \boldsymbol{B}=\frac{R g \mathcal{J}|\nabla \theta|^{2}}{X^{2}} \nabla \psi-\frac{R g \mathcal{J}(\boldsymbol{\nabla} \psi \cdot \nabla \theta)}{X^{2}} \nabla \theta+f(\nabla \psi \cdot \nabla \theta) \nabla \phi .
$$

Note, however, that $\mathbf{e}_{\theta}$ does not lie completely in a toroidal cross section.

\subsection{Perturbed magnetic field}

Another interesting quantity is the perturbed magnetic field, $\boldsymbol{Q}=\boldsymbol{\nabla} \times(\boldsymbol{\xi} \times \boldsymbol{B})$, which can be measured with Mirnov loops.

$$
\begin{aligned}
\boldsymbol{Q}= & {\left[\frac{\mathcal{J} f}{X^{2} g R}(\nabla \psi \cdot \nabla \theta) \frac{\partial g}{\partial \psi} \xi_{\psi}^{P}+\frac{\mathcal{J} g}{X^{2} R}(\nabla \psi \cdot \nabla \theta) \frac{\partial}{\partial \psi}\left(\frac{f \xi_{\psi}^{P}}{g}\right)+\frac{\mathcal{J} f}{X^{2} R}|\nabla \theta|^{2} \frac{\partial \xi_{\psi}^{P}}{\partial \theta}\right.} \\
& \left.+\frac{f^{2}}{X^{2} g R} \frac{\partial \xi_{\psi}^{P}}{\partial \phi}+\frac{\mathcal{J}^{2} B^{2}}{X^{2} g R^{2}}\left(\mid \nabla \theta !^{2} \frac{\partial \xi_{\psi}^{P}}{\partial \phi}-i \nabla \psi \cdot \nabla \theta \frac{\partial \xi_{s}^{P}}{\partial \phi}\right)\right] \nabla \psi \\
& -\left[\frac{\mathcal{J} f}{X^{2} g R}|\nabla \psi|^{2} \frac{\partial g}{\partial \psi} \xi_{\psi}^{P}+\frac{\mathcal{J} g}{X^{2} R},\left.\nabla \psi\right|^{2} \frac{\partial}{\partial \psi}\left(\frac{f \xi_{\psi}^{P}}{g}\right)\right. \\
& \left.+\frac{\mathcal{J} f}{X^{2} R}(\nabla \psi \cdot \nabla \theta) \frac{\partial \xi_{\psi}^{P}}{\partial \theta}+\frac{\mathcal{J}^{2} B^{2}}{X^{2} g R^{2}}\left(\nabla \psi \cdot \nabla \theta \frac{\partial \xi_{\psi}^{P}}{\partial \phi}-i|\nabla \psi|^{2} \frac{\partial \xi_{s}^{P}}{\partial \phi}\right)\right] \nabla \theta
\end{aligned}
$$




$$
\begin{aligned}
& +\left[\frac{f \xi_{\psi}^{P}}{g R^{2}}\left\{\frac{\partial}{\partial \psi}\left(\frac{f \mathcal{J}}{X^{2}}|\nabla \psi|^{2}\right)+\frac{\partial}{\partial \theta}\left(\frac{f \mathcal{J}}{X^{2}} \nabla \psi \cdot \nabla \theta\right)\right\}+\frac{f}{R^{2}}|\nabla \psi|^{2} \frac{\partial}{\partial \psi}\left(\frac{f \xi_{\psi}^{P}}{g}\right)\right. \\
& \left.-\frac{X^{2}}{\mathcal{J} R^{2}}\left\{\frac{\partial}{\partial \psi}\left(\frac{\mathcal{J} B^{2} \xi_{\psi}^{P}}{g}\right)+i \frac{\partial}{\partial \theta}\left(\frac{\mathcal{J} B^{2} \xi_{s}^{P}}{g}\right)\right\}+\frac{f^{2}}{g R^{2}}(\nabla \psi \cdot \nabla \theta) \frac{\partial \xi_{\psi}^{P}}{\partial \theta}\right] \nabla \phi .
\end{aligned}
$$

The most useful components of $Q$ for experimental measurements are

$$
Q_{\psi}=\frac{\boldsymbol{Q} \cdot \boldsymbol{\nabla} \psi}{|\boldsymbol{\nabla} \psi|}, \quad Q_{\theta}=\frac{\boldsymbol{Q} \cdot(\boldsymbol{\nabla} \phi \times \nabla \psi)}{|\boldsymbol{\nabla} \phi||\nabla \psi|}, \quad Q_{\phi}=\frac{\boldsymbol{Q} \cdot \boldsymbol{\nabla} \phi}{|\boldsymbol{\nabla} \phi|},
$$

where the component $Q_{\theta}$ now lies in a toriodal cross section. These components are

$$
\begin{gathered}
Q_{\psi}=\frac{1}{X^{2}|\nabla \psi|}\left\{\frac{2 \pi f}{v} \frac{\partial \xi_{\psi}^{P}}{\partial \theta}+g \frac{\partial \xi_{\psi}^{P}}{\partial \phi}\right\}, \\
Q_{\theta}=-\frac{|\nabla \psi|}{X R}\left[f \frac{\partial \xi_{\psi}^{P}}{\partial \psi}+\xi_{\psi}^{P} \frac{\partial f}{\partial \psi}\right]-\frac{f}{X R|\nabla \psi|}(\nabla \psi \cdot \nabla \theta) \frac{\partial \xi_{\psi}^{P}}{\partial \theta} \\
-\frac{v^{2}}{4 \pi^{2} g R^{3}}\left[f^{2}|\nabla \psi|^{2}+R^{2} g^{2}\right]\left[(\nabla \psi \cdot \nabla \theta) \frac{\partial \xi_{\psi}^{P}}{\partial \phi}-i|\nabla \psi|^{2} \frac{\partial \xi_{s}^{P}}{\partial \phi}\right], \\
Q_{\phi}=+\frac{f X^{2} \xi_{\psi}^{P}}{g R^{2}}\left\{\frac{\partial}{\partial \psi}\left(\frac{f \mathcal{J}}{X^{2}}|\nabla \psi|^{2}\right)+\frac{\partial}{\partial \theta}\left(\frac{f \mathcal{J}}{X^{2}} \nabla \psi \cdot \nabla \theta\right)\right\} \\
+\frac{f X^{2}}{R^{2}}|\nabla \psi|^{2} \frac{\partial}{\partial \psi}\left(\frac{f \xi_{\psi}^{P}}{g}\right)+\frac{f^{2} X^{2}}{g R^{2}}(\nabla \psi \cdot \nabla \theta) \frac{\partial \xi_{\psi}^{P}}{\partial \theta} \\
-\frac{X^{4}}{\mathcal{J} R^{2}}\left\{\frac{\partial}{\partial \psi^{\prime}}\left(\frac{\mathcal{J} B^{2} \xi_{\psi}^{P}}{g}\right)+i \frac{\partial}{\partial \theta}\left(\frac{\mathcal{J} B^{2} \xi_{s}^{P}}{g}\right)\right\}
\end{gathered}
$$

\subsection{Evaluation of compressibility}

The post-processor can also be used to determine how well the incompressibility assumption, $\boldsymbol{\nabla} \cdot \boldsymbol{\xi}=0$, is satisfied. This is done by calculating

$$
\begin{aligned}
\nabla \cdot \boldsymbol{\xi}= & \frac{1}{X^{2} R} \frac{\partial\left(X^{2} \xi_{\psi}^{P}\right)}{\partial \psi}+\frac{i}{X^{2} R} \frac{\partial\left(X^{2} \xi_{s}^{P}\right)}{\partial \theta} \\
& +\frac{v f}{2 \pi g R^{3}}\left[\nabla \psi \cdot \nabla \theta \frac{\partial \xi_{\psi}^{P}}{\partial \phi}-i|\nabla \psi|^{2} \frac{\partial \xi_{s}^{P}}{\partial \phi}\right] \\
& +\frac{i 2 \pi R f}{v X^{2}} \frac{\partial \xi_{B}^{P}}{\partial \theta}+\frac{i R g}{X^{2}} \frac{\partial \xi_{B}^{P}}{\partial \phi}
\end{aligned}
$$




\section{Applications}

We row demonstrate some applications of computing these quantities from the PEST output.

The new Fourier decomposition of the different projections of the displacement vector give a better physical picture for analysis of the instability's mode structure.

$\boldsymbol{Q}$ can be calculated at any point inside the plasma and compared with experimentally measured values. The components of $\boldsymbol{Q}$, may also be Fourier decomposed to look at the mode structure. As an example of more direct comparision with experiments, the signal $\partial \bar{B} / \partial t$ from a poloidal array of Mirnov coils can be Fourier decomposed in $\theta$ to find the amplitudes of the varıous poloidal modes. These measurements of the perturbed field can then be compared with $Q_{\alpha, m n}(\psi)$ by noting that the $m$ th component of the field decays as $r^{-(m+1)}$.

$$
Q_{\alpha, m n}(r, \theta, \phi)=Q_{\alpha, m n}(a, 0,0)\left(\frac{a}{r}\right)^{m+1} \cos (m \theta+n \phi)
$$

where $a$ is the plasma minor radius.

The importance of the compressible term in $\delta W$ can be measured by comparing the $\gamma p|\boldsymbol{\nabla} \cdot \boldsymbol{\xi}|^{2}$ term with the other terms in $\delta W$,

$$
\begin{gathered}
\delta W=\frac{1}{2} \int_{\text {plasme }} d V\left[\frac{\left|Q_{\perp}\right|^{2}}{\mu_{0}}+\frac{B^{2}}{\mu_{0}}\left|\nabla \cdot \xi_{\perp}+2 \xi_{\perp} \cdot \kappa\right|^{2}\right. \\
\quad-2\left(\xi_{\perp} \cdot \nabla p\right)\left(\xi_{\perp}^{*} \cdot \kappa\right)-J_{\|}\left(\xi_{\perp}^{*} \times \hat{b}\right) \cdot Q_{\perp} \\
\left.+\gamma p|\nabla \cdot \xi|^{2}\right] .
\end{gathered}
$$

\subsection{Pressure modified kink mode}

We first consider a large aspect ratio $(R / a=10)$ circular cross-section discharge, which is chosen to illu: ate pressure modification of an external kink mode. The parameters defining this case are: $\beta=0.69 \%, \beta_{p}=4.97, q(0)=1.05$, $q(1)=2.85$, Troyon factor $C_{T} \equiv \beta a B / I=3.69$. This configuration is unstable with respect to the global instability shown in Fig. 1 with an eigenvalue $\rho a^{2} \omega^{2} / \mu_{c} B^{2}=0.247$. The Fourier decomposition of the displacement that is presently available from the PEST code, $\xi_{\psi}^{P}$ of Eq. (3), is shown in Fig. 2. The decomrosition of the properly normalized component, $\xi_{\psi}$ of Eq. (6), is shown in Fig. 3. The decomposition in the orthogonal projection, $\xi_{r}$ of Eq. (8), is very similar in both magnitude and form to Fig. 3. The change in normalization between $\xi_{\psi}^{P}$ and $\xi_{\psi}$ modifies the relative magnitudes and intrcluces sign changes in the modes as well as an $m=0$ component. This indicates that the lower- $m$ modes contribute 
much more to the instability than one would have believed from looking at the original decomposition. The behavior of the displacement $\xi_{\theta}$ of Eq. (8) is given in Fig. 4. It has some of the properties of $\xi_{\psi}$ and $\xi_{r}$, but is far from identical. We do not show the component $\xi_{b}$, which represents the flow along the field line that is necessary to minimize $\boldsymbol{\nabla} \cdot \boldsymbol{\xi}$, since it is small. The quantity $\boldsymbol{\nabla} \cdot \boldsymbol{\xi}$ on several flux. surfaces is illustrated in Fig. 5. The components of the perturbed field, $Q_{\psi}$ and $Q_{\theta}$, that are associated with this displacement are shown in Figs. 6 and 7 . The Fourier decompositions of $Q_{\psi}$ and $Q_{\theta}$ are shown in Figs. 8 and 9. Comparison of these with $\xi_{\psi}$ in Fig. 3 shows somewhat different structures.

\subsection{External kink mode}

Our second illustration is also a large aspect ratio circular cross-section plasma. It is unstable with respect to an $m=3$ current driven kink mode. The discharge has $\beta=0, q(0)=1.05$ and $q(1)=2.95$. The fastest growing instability, with $\rho a^{2} \omega^{2} / \mu_{0} B^{2}=0.004$, is localized near the plasma surface as can be seen in Fig. 10 . The perturbed field on a flux surface, Fig. 11, shows a nearly pure $m=3$ mode that is localized near the edge. Nevertheless, plots of a Fourier decomposition of the perturbed magnetic field in Figs. 12 and 13 show coupling to neighboring harmonics.

\subsection{Ballooning mode}

Our third case is a low aspect ratio $(R / a=3.33)$, elliptic cross-section discharge chosen to illustrate a high- $n$ ballooning mode instability. The plasma boundary is defined by

$$
\begin{gathered}
X=R+a \cos (\theta+\delta \sin \theta), \\
Z=a \sin (\theta+\delta \sin \theta),
\end{gathered}
$$

with $\kappa=1.5$ and $\delta=0.26$. We have $\beta=6.33 \%, \beta_{p}=2.62, q(0)=1.15$, $q(1)=4.54$, and $C_{T}=6.92$. The dominant instability, Fig. 14, has a large growth rate, $\rho a^{2} \omega^{2} / \mu_{0} B^{2}=1.10$, and has a strong ballooning character. The Fourier decompositions of the displacement vectors normal to the magnetic field, $\xi_{\mathrm{r}}$ anu $\xi_{\theta}$, are given in Figs. 15 and 16 , and $\boldsymbol{\nabla} \cdot \boldsymbol{\xi}$ is given in Fig. 17. These, together with pictures of the perturbed magnetic field, such as Figs. 18 and 19, show that this ballooning mode contains much more structure than might have been anticipated.

An application of this processor is to compare the contributions from the various terms in $\delta W$, Eq. (17). For example, the comparison of the $\left|\boldsymbol{Q}_{\perp}\right|^{2} / \mu_{\mathrm{o}}$ term with $\gamma p|\nabla \cdot \boldsymbol{\xi}|^{2}$ on a surface in Fig. 20 shows that the sloshing of sound waves to equilize 
the pressure on the magnetic surfaces can be roughly $5 \%$ of the stabilization effect associated with shear Alfvén waves.

\section{Summary}

We can now calculate many quantities of physical interest using given tokamak equilibrium values and the eigenfunctions $\xi$ found by the PEST code. A pplication of this program has already proven to be useful in analysis of data from PBX-M plasmas[2].

As an extension of this work, values of the perturbed field, $Q$, can be predicted for a given instability at any point outside the plasma by using the extrapolation of Eq. (16). This will provide direct comparison with experirnental measurements.

At present, we calculate and plot only some of the terms in $\delta W$. Calculating all of these terms will provide an opportunity to investigate the sources of energy drive and stabilization for a particular unstable mode, shedding light on mechanisms for optimizing the stability properties of a configuration.

\section{Acknowledgment}

This work was supported by the U. S. Department of Energy contract No. DEAC02-76-CHO-3073 with Pris ceton University. Much of the work was performed while one of us (SP) was under appointment to the Magnetic Fusion Science Fellowship program, U. S. Department of Energy. 


\section{References}

1. R. C. Grimin, J. M. Greene, and J. L. Johnson, in Methods in Computational Physics. Edited by J. Killeen (Academic Press, New York, 1976) Vol. 16, p. 253.

2. D. W. Roberts, Ph. D. Thesis, Princeton University, 1991. 


\section{Figures}

Fig. 1. Displacement vector for the pressure modified kink mode. The length denotes the magnitude of the displacement at a point located at the start of the arrow.

Fig. 2. Fourier decomposition of the unncrmalized perturbation, $\xi_{\psi}^{P}$, for the pressure modified kink mode.

Fig. 3. Fourier decomposition of the normalized perturbation, $\xi_{\psi}$, for the pressure modified kink mode.

Fig. 4. Fourier decomposition of $\xi_{\theta}$, the normalized orthogonal perturbation in the $B \times \nabla \psi$ direction, for the pressure modified kink mode.

Fig. 5. The function $\boldsymbol{\nabla} \cdot \boldsymbol{\xi}$ for the pressure modified kink mode as a function of $\theta$ on a magnetic surface.

Fig. 6. Contour plut of $Q_{\psi}$ for the pressure modified kink mode. The solid lines denote fields in the positive $Q_{\psi}$ direction; the dotted lines are for fields in the opposite direction.

Fig. 7. Contour plot of $Q_{\theta}$ for the pressure modified kink mode.

Fig. 8. Fourier decomposition of the perturbed field, $Q_{\psi}$, perpendicular to a flux surface for the pressure modified kink mode.

Fig. 9. Fourier decomposition of the component of the perturbed field, $Q_{\theta}$, for the pressure modified kink mode.

Fig. 10. Displacement vector for the external kink mode.

Fig. 11. The perturbed field $Q_{\theta}$ as a function of $\theta$ for the external kink mode.

Fig. 12. Fourier decomposition of the perturbed field $Q_{\psi}$ for the external kink mode.

Fig. 13. Fourier decomposition of the perturbed magnetic field $Q_{\theta}$ for the external kink mode.

Fig. 14. Displacement vector for the ballooning mode.

Fig. 15. Fourier decomposition of the normalized orthogonal radial perturbation, $\xi_{r}$, for the ballooning mode. 
Fig. 16. Fourier decomposition of the normalized orthogonal perturbation $\xi_{\theta}$ for the ballooning mode.

Fig. 17. The function $\boldsymbol{\nabla} \cdot \boldsymbol{\xi}$ for the ballooning mode as a function of $\theta$ on a magnetic surface.

Fig. 18. Contour plot of $Q_{\psi}$ for the ballooning mode.

Fig. 19. $Q_{\theta}$ as a function of $\theta$ for the ballooning mode.

Fig. 20. The $\left|Q_{\perp}\right|^{2} / \mu_{o}$ and $\gamma p|\nabla \cdot \boldsymbol{\xi}|^{2}$ terms in $\delta W$ on a surface with $\psi=0.1$ for the ballooning mode. 


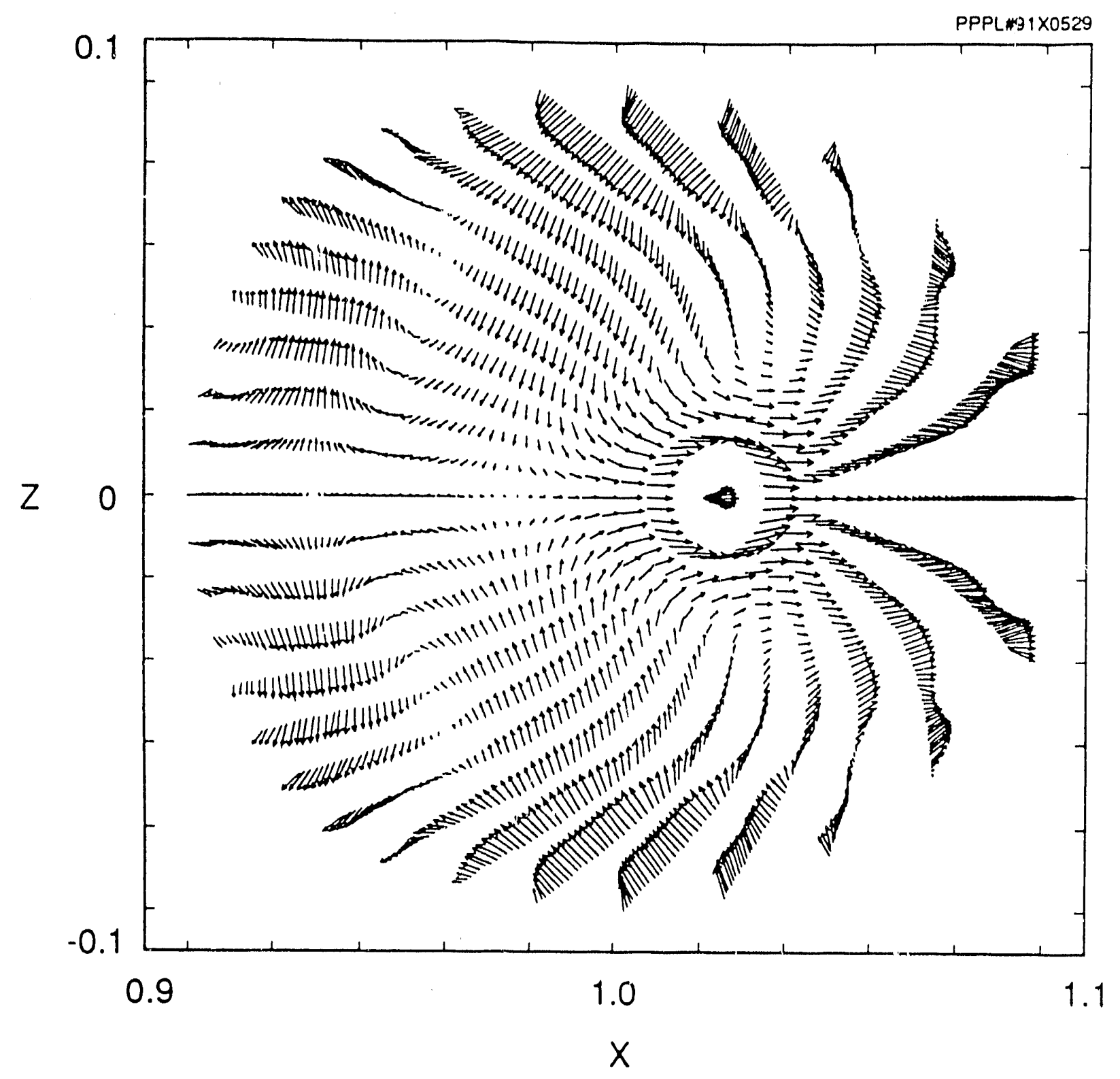

Fig. 1 


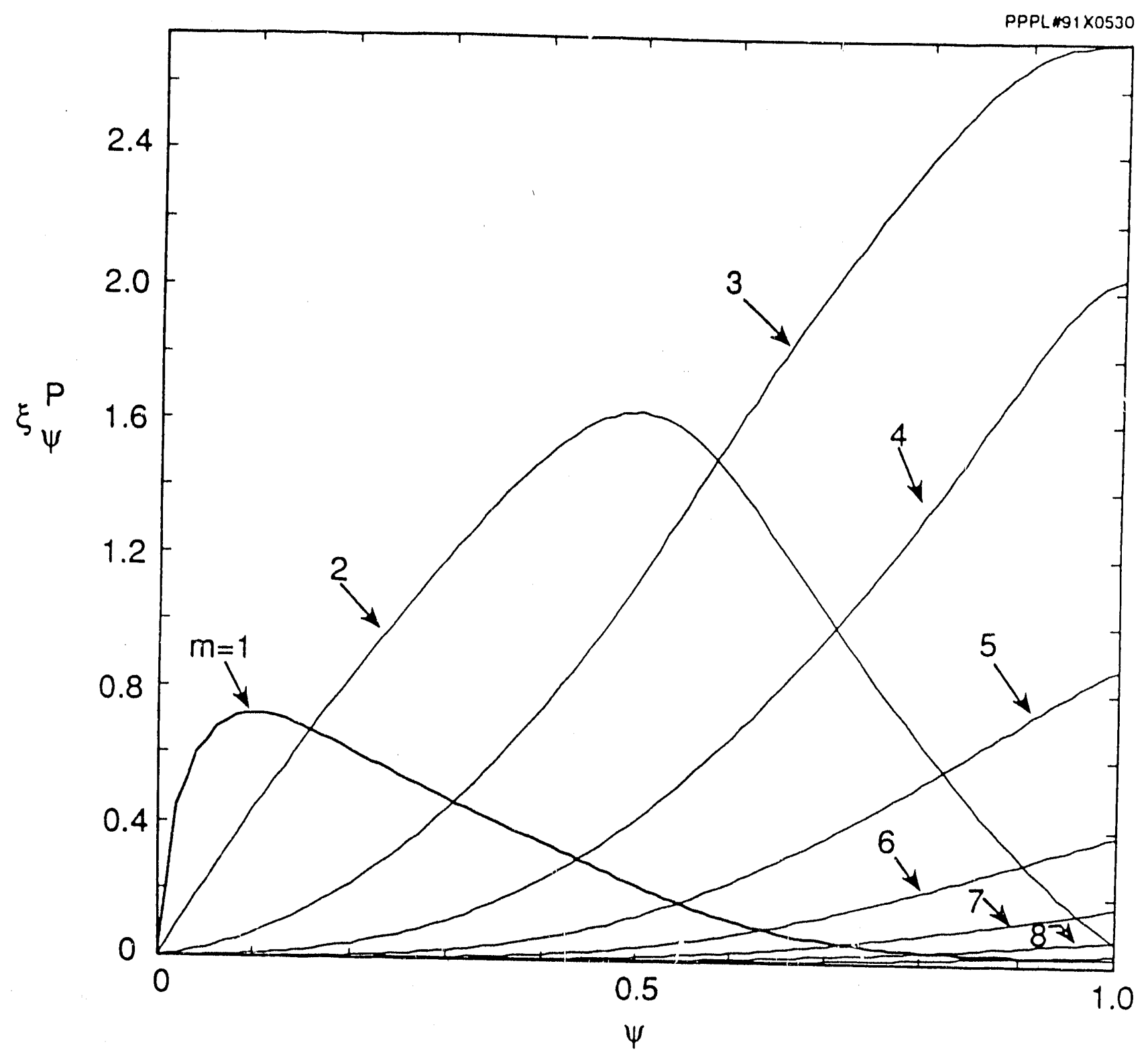

Fig. 2 


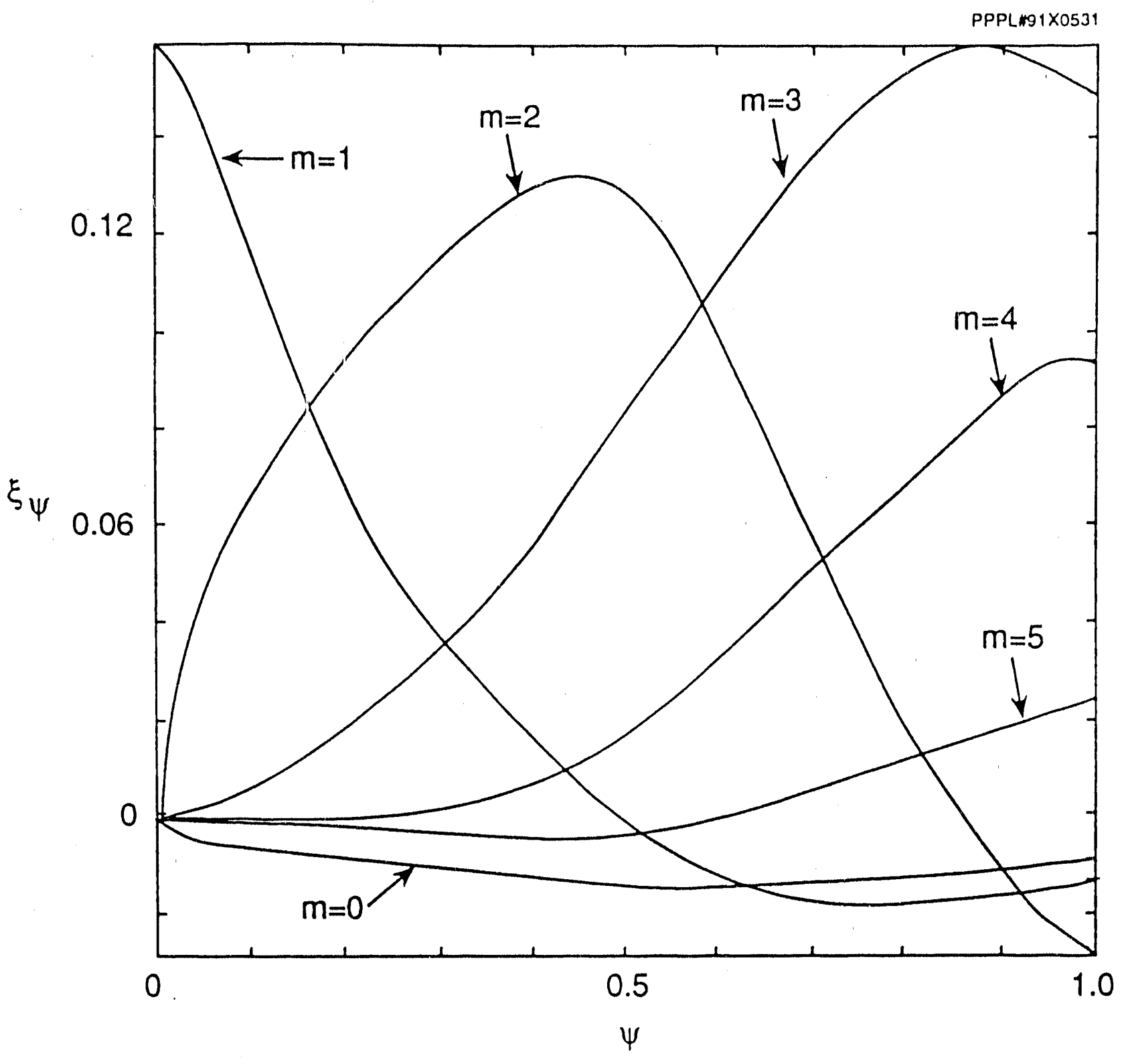

Fig. 3 


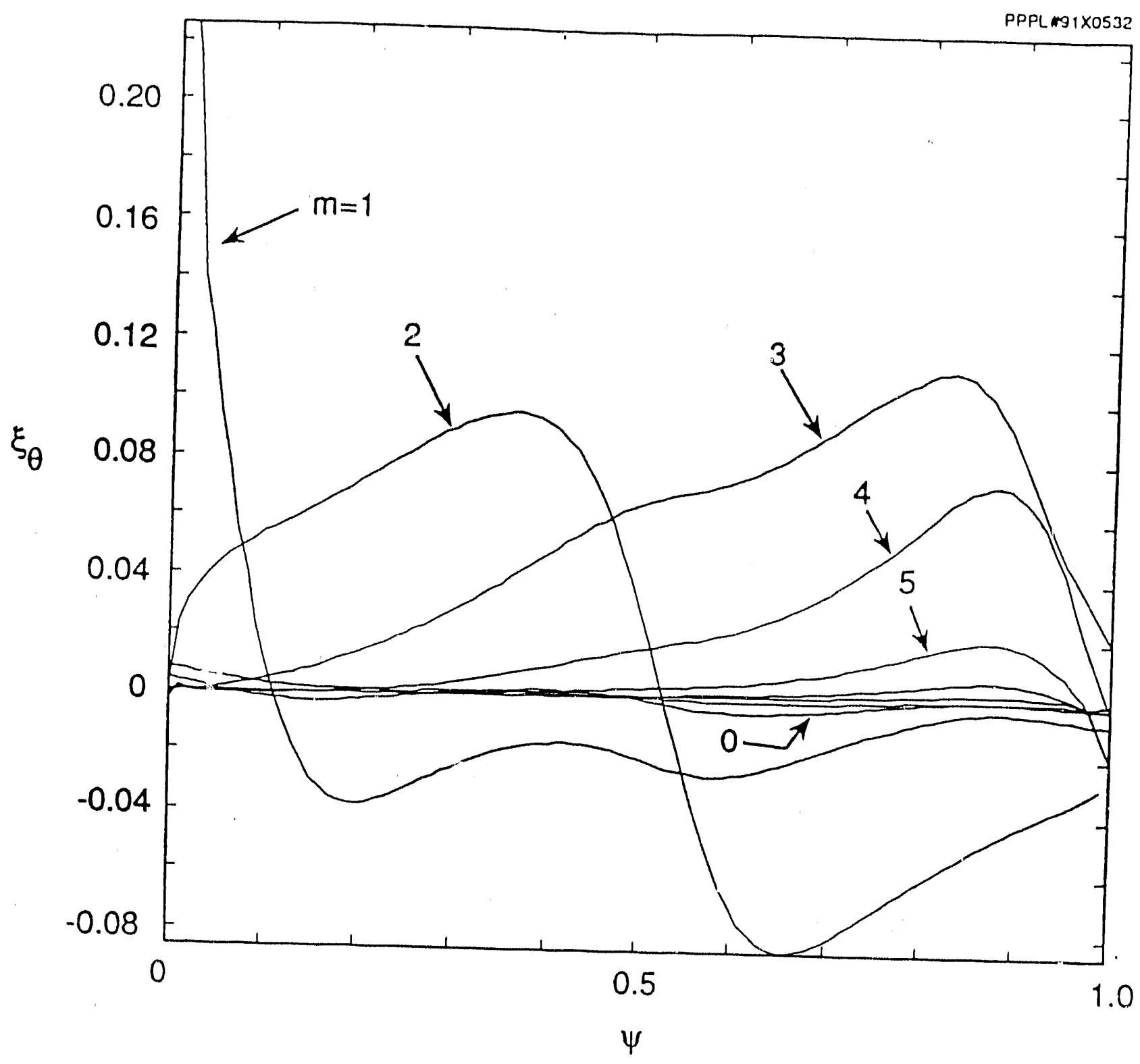

Fig. 4 


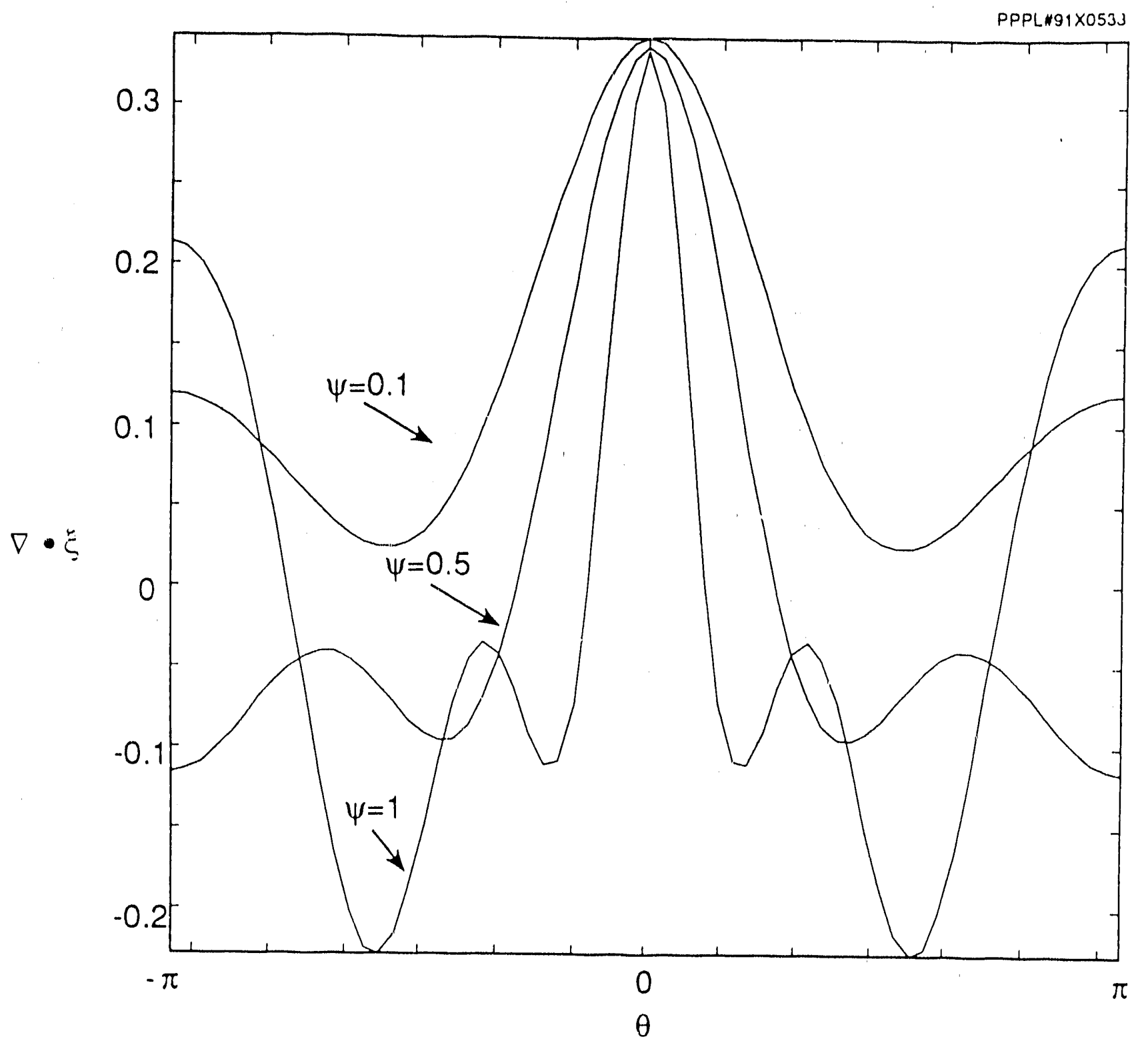

F1g، 5 


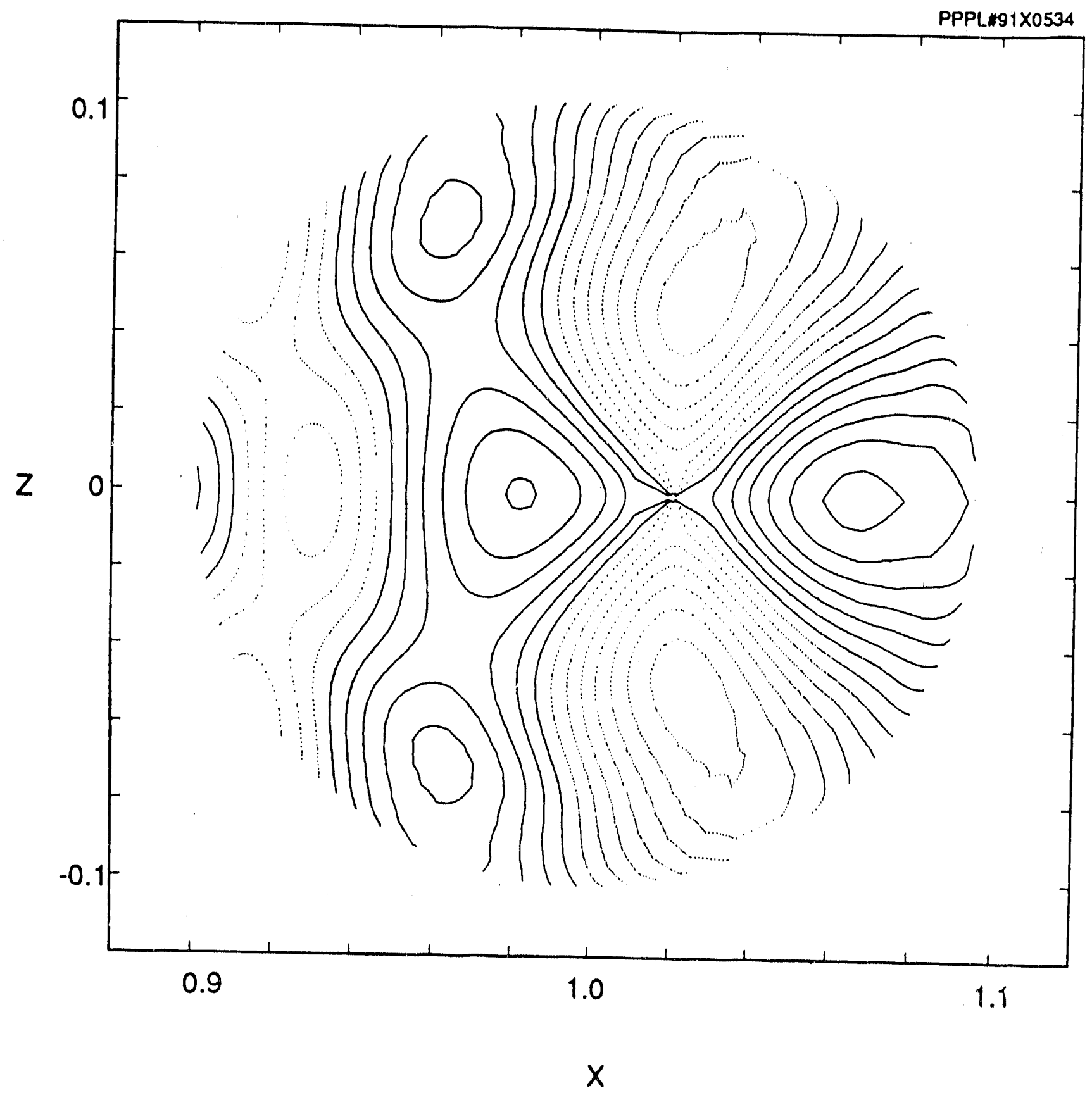

Fig. 6 


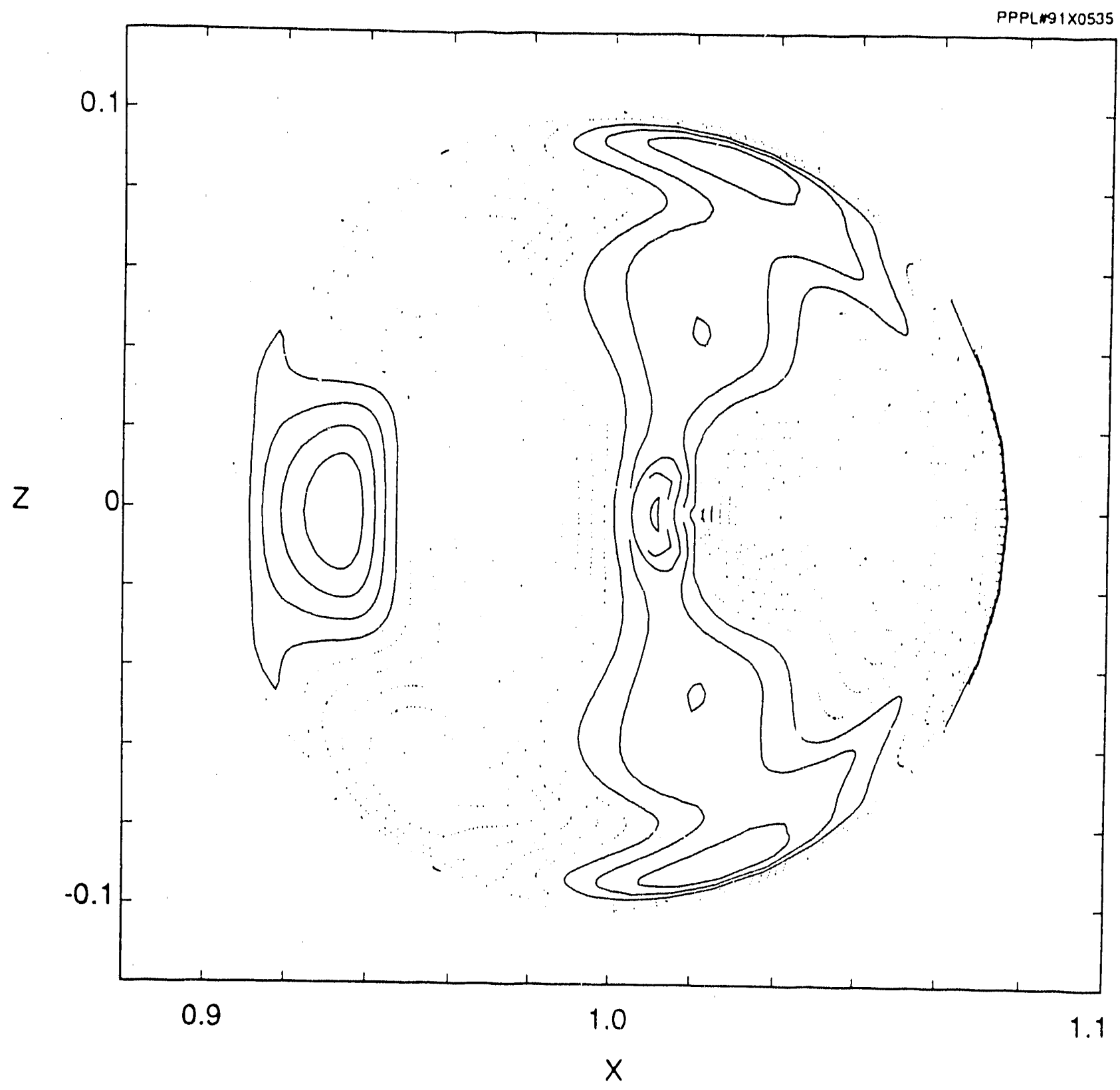

Fig. 7 


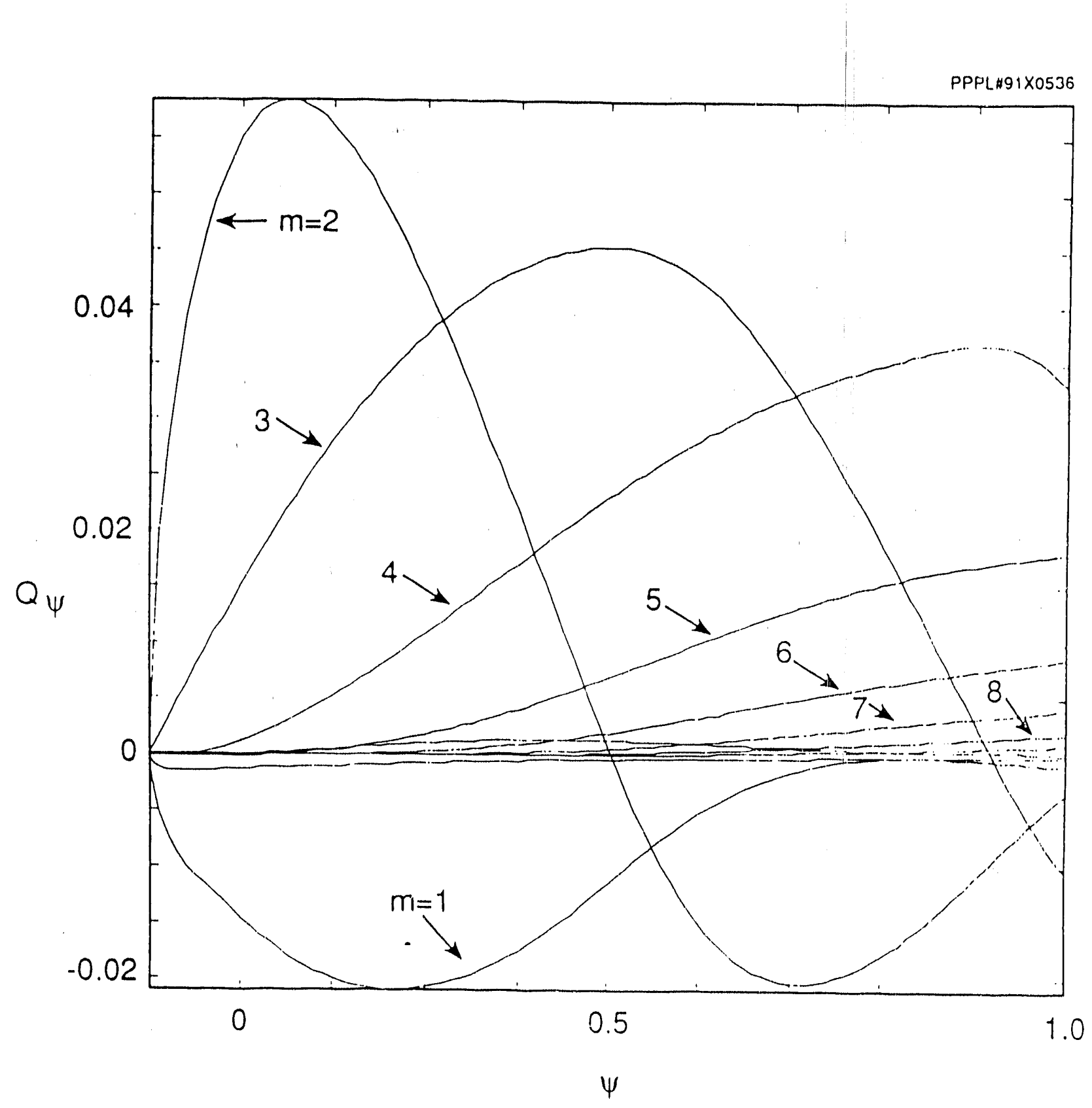

F1g. 8 


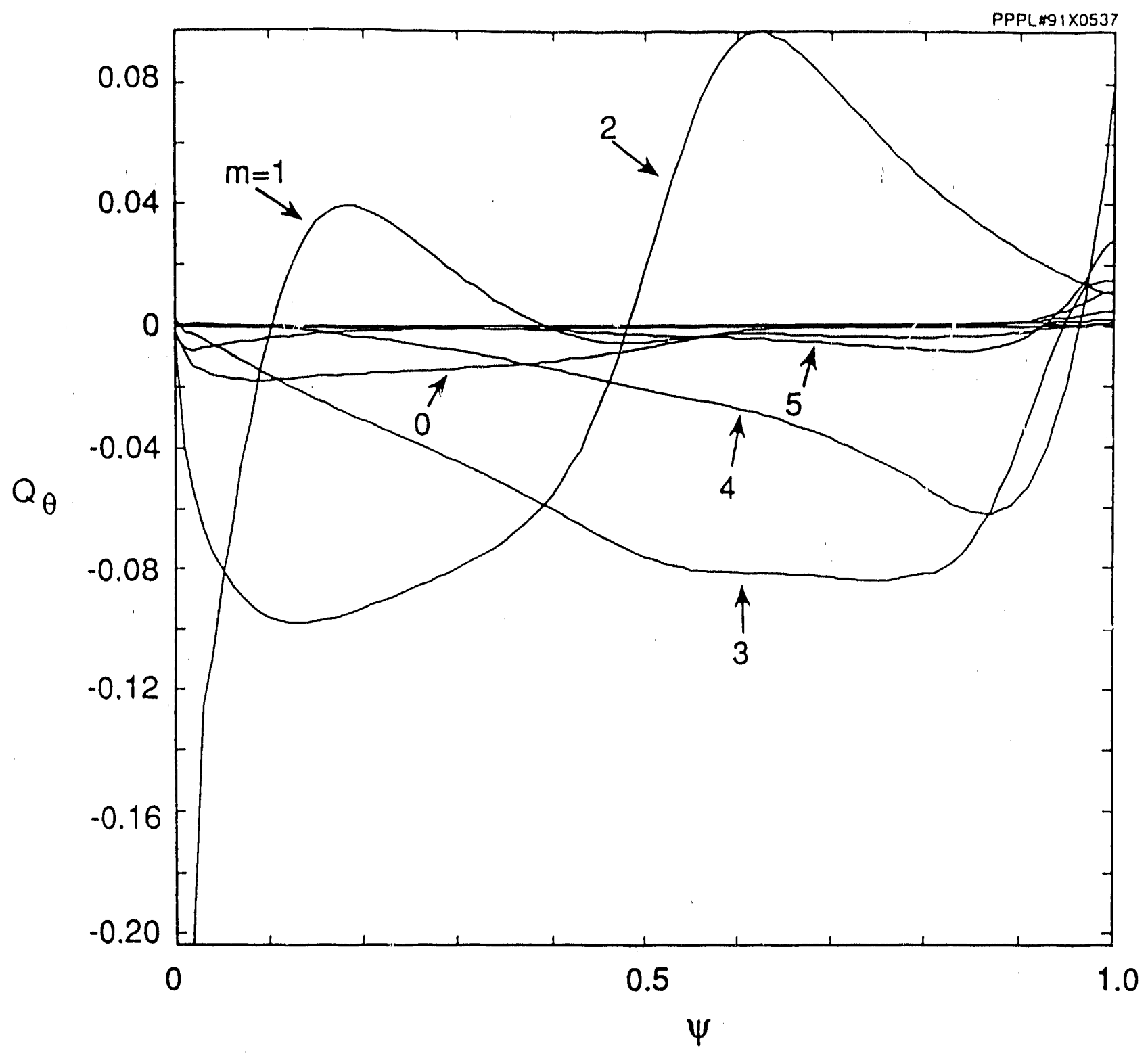

Fig. 9 


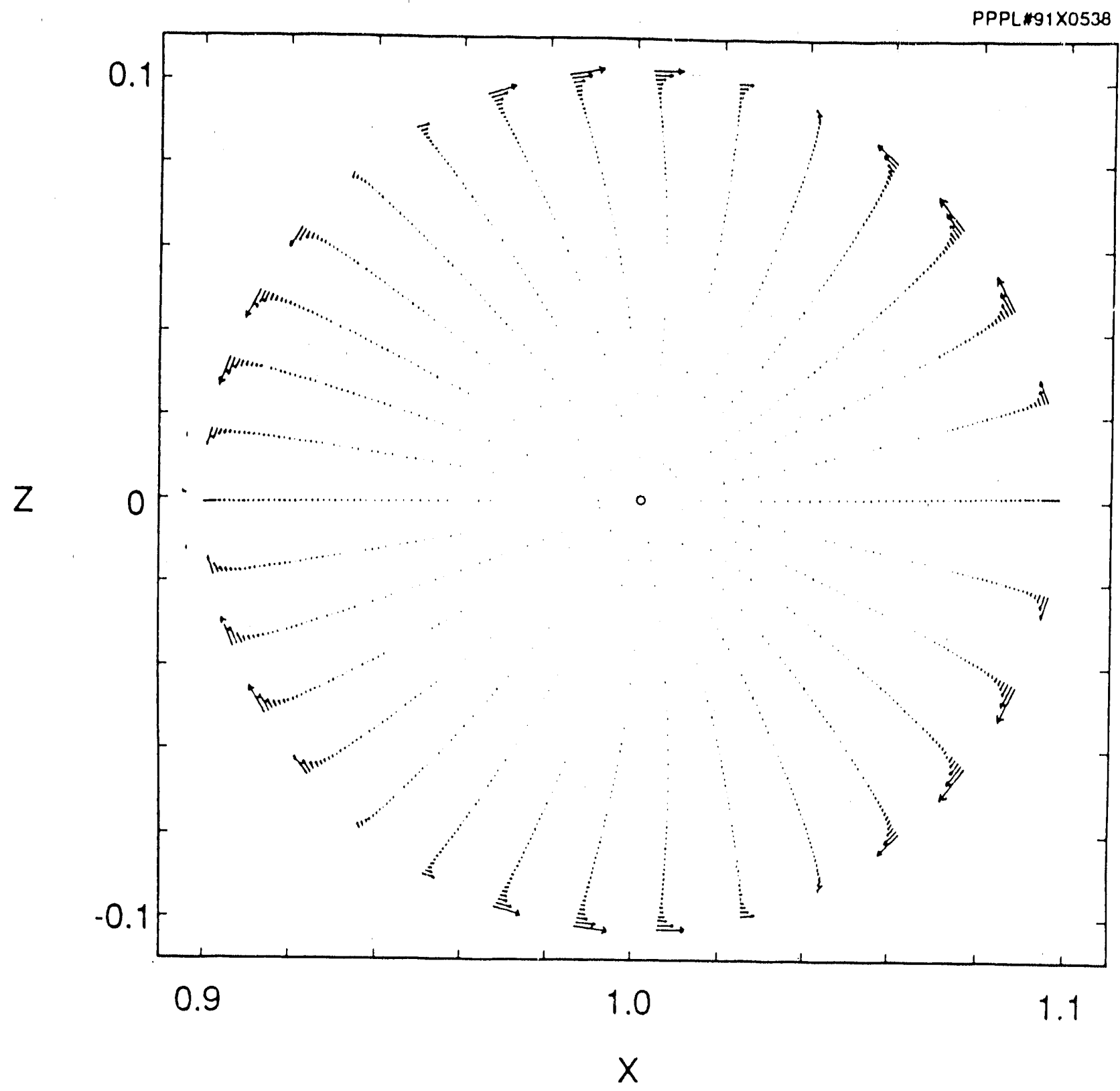

Fig. 10 


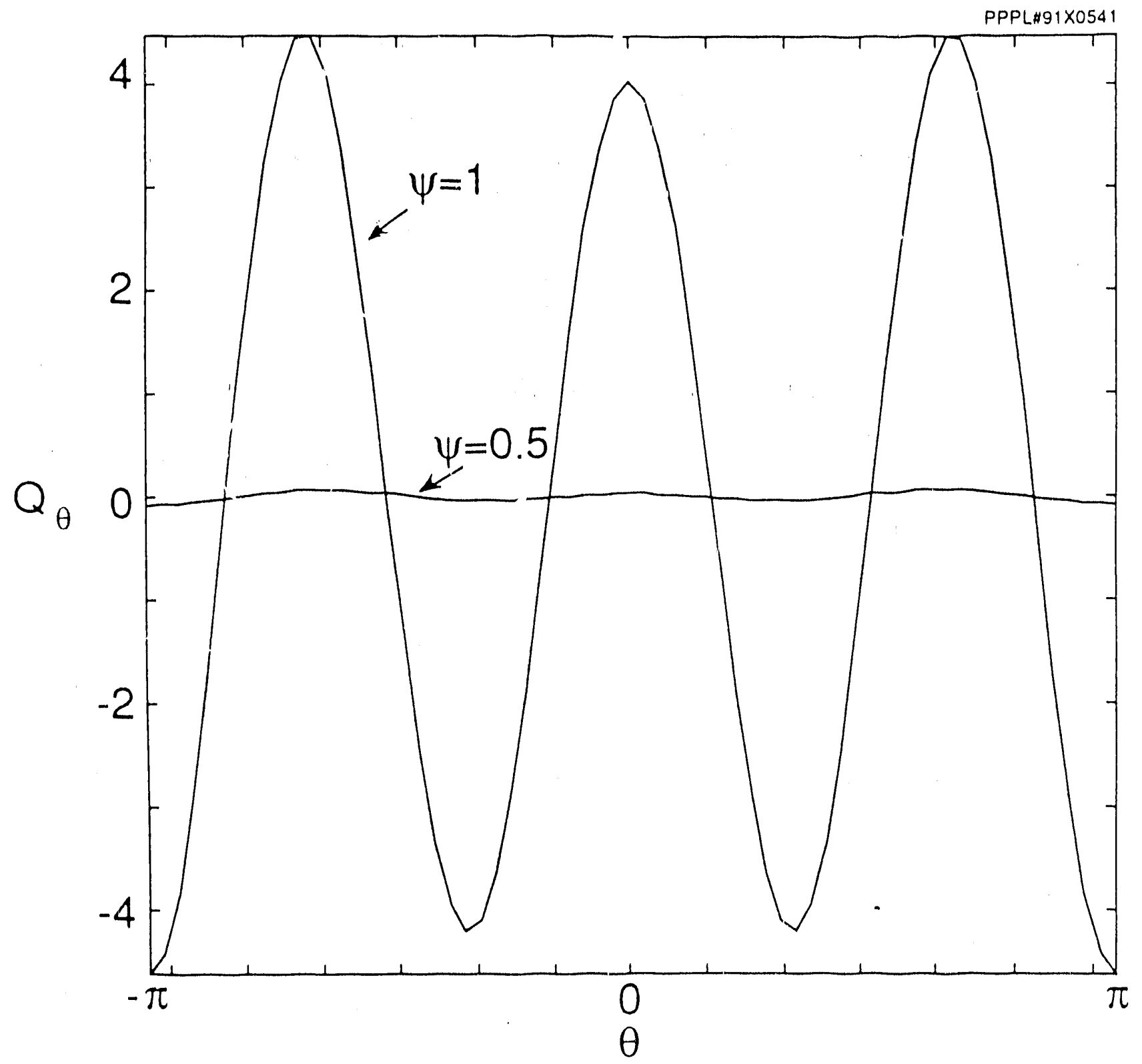

Fig. 11 


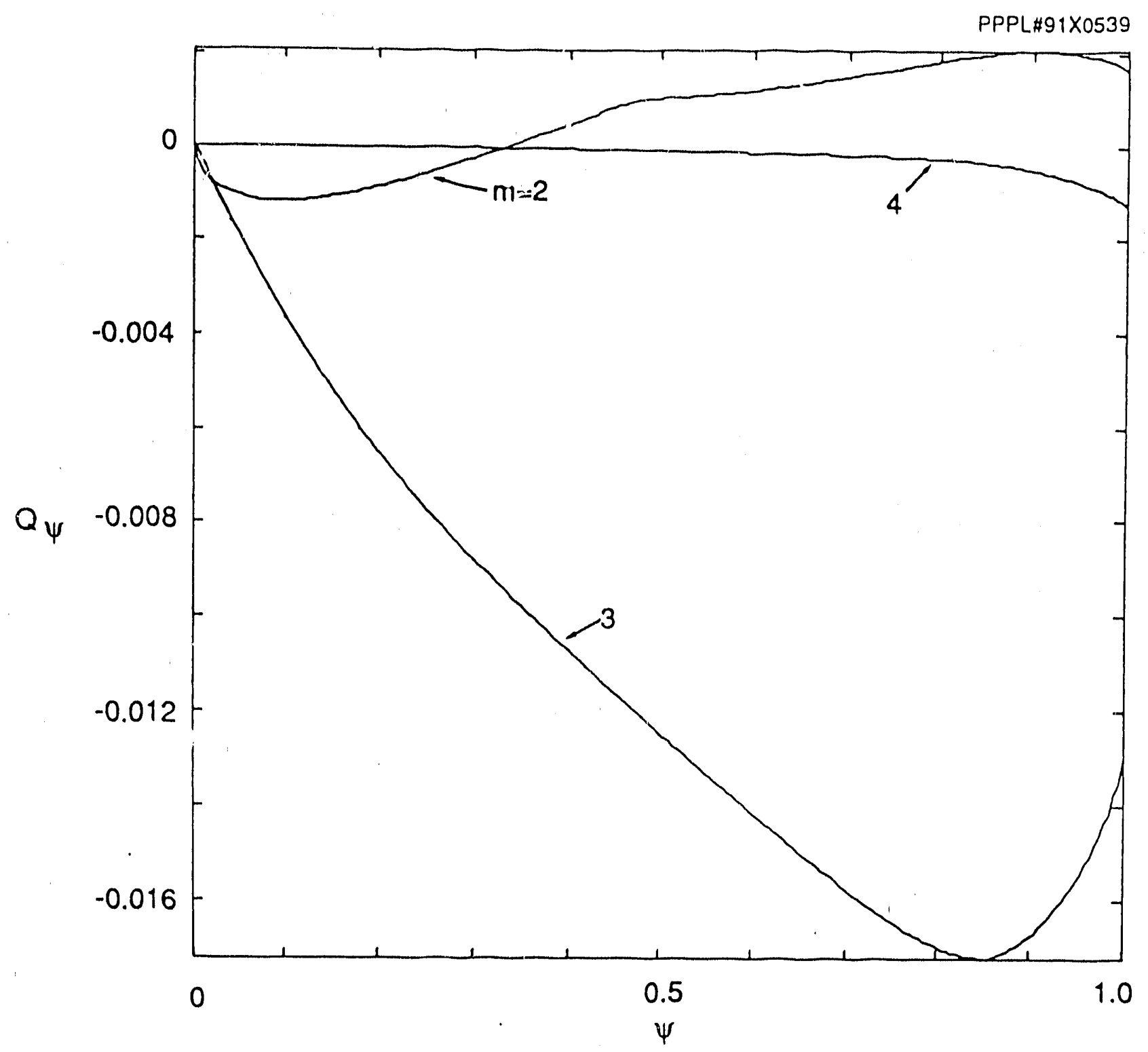

Fig. 12 


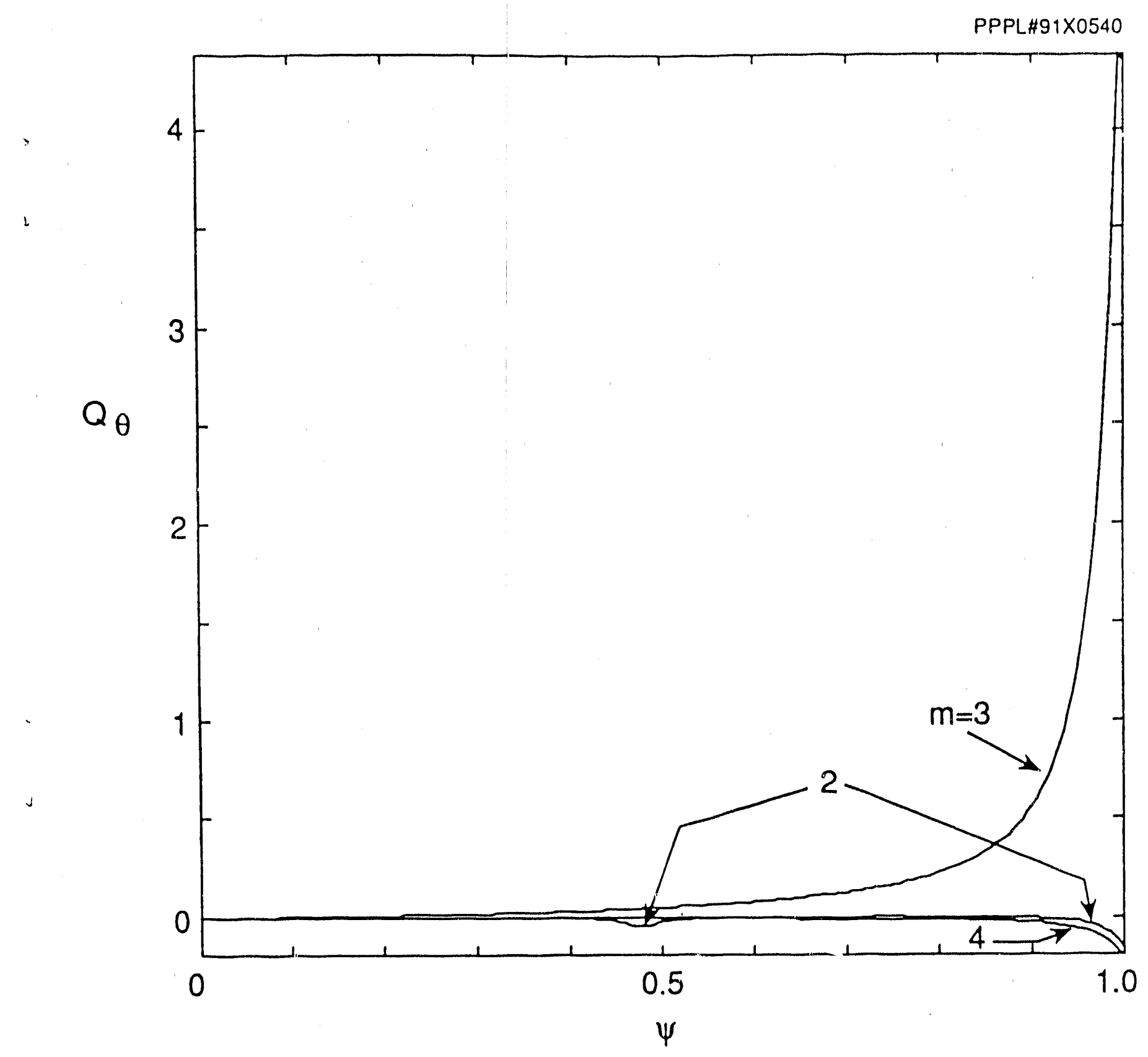

F1g. 13 


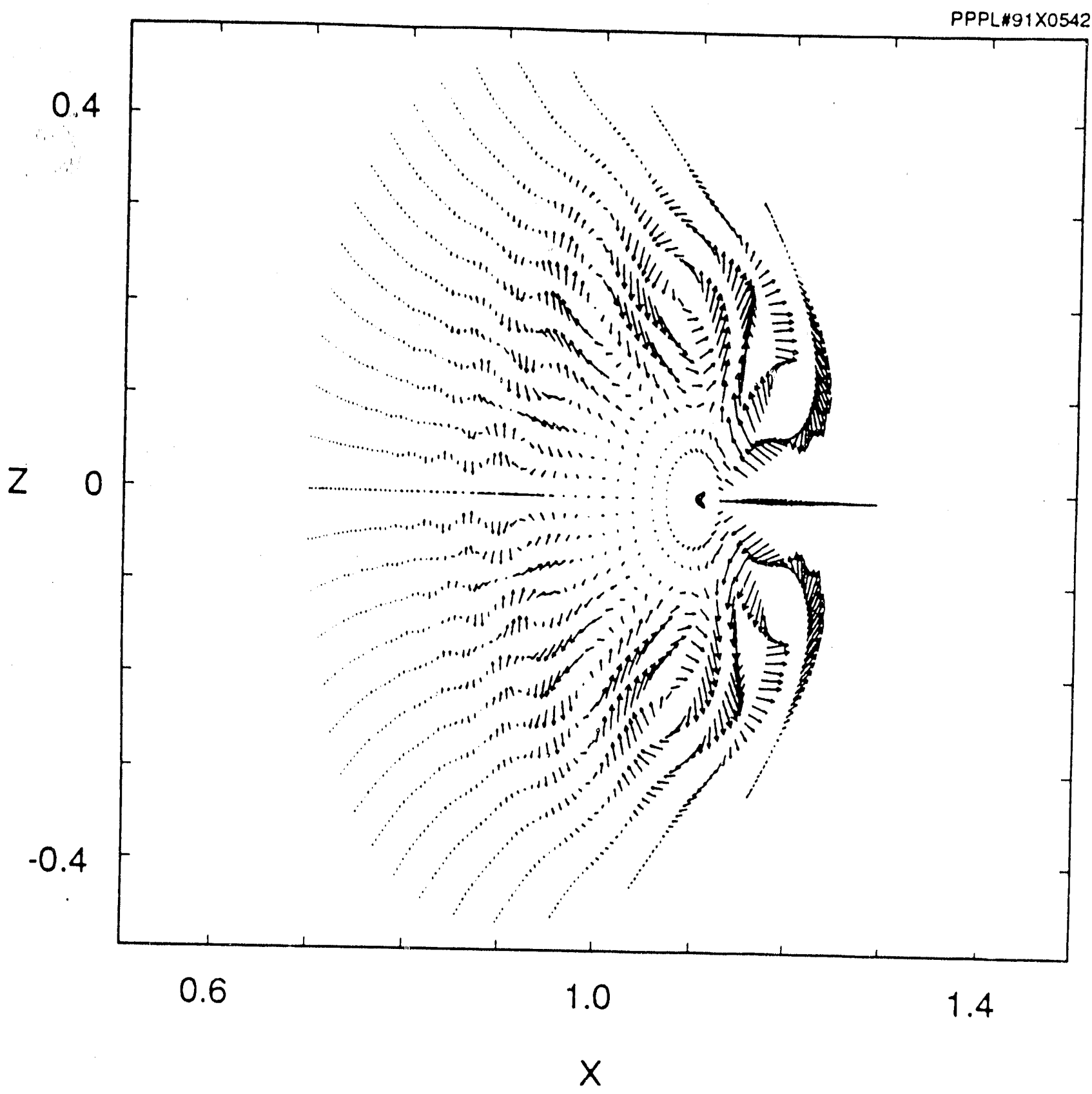

FIg. 14 


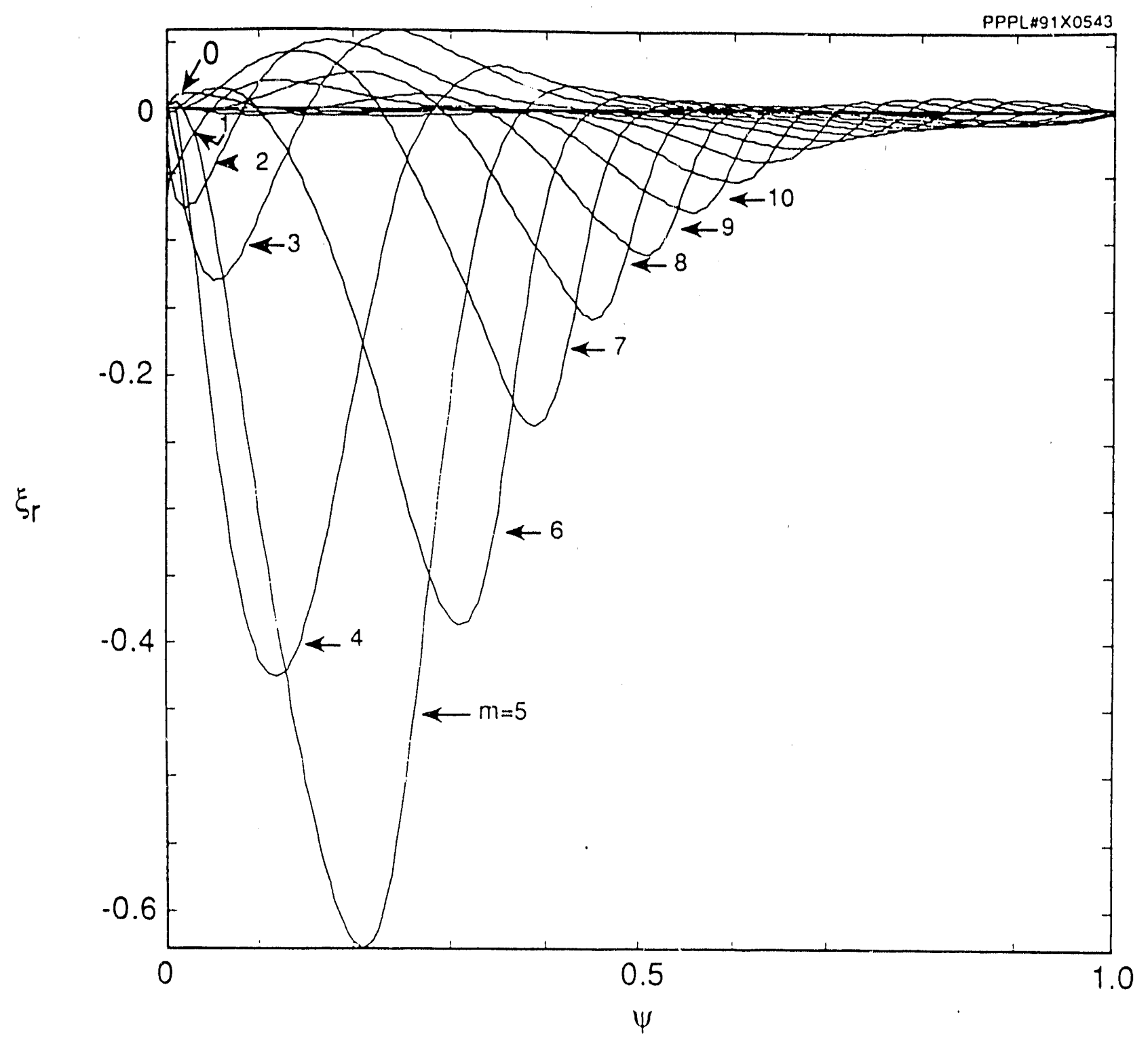

Fig. 15 


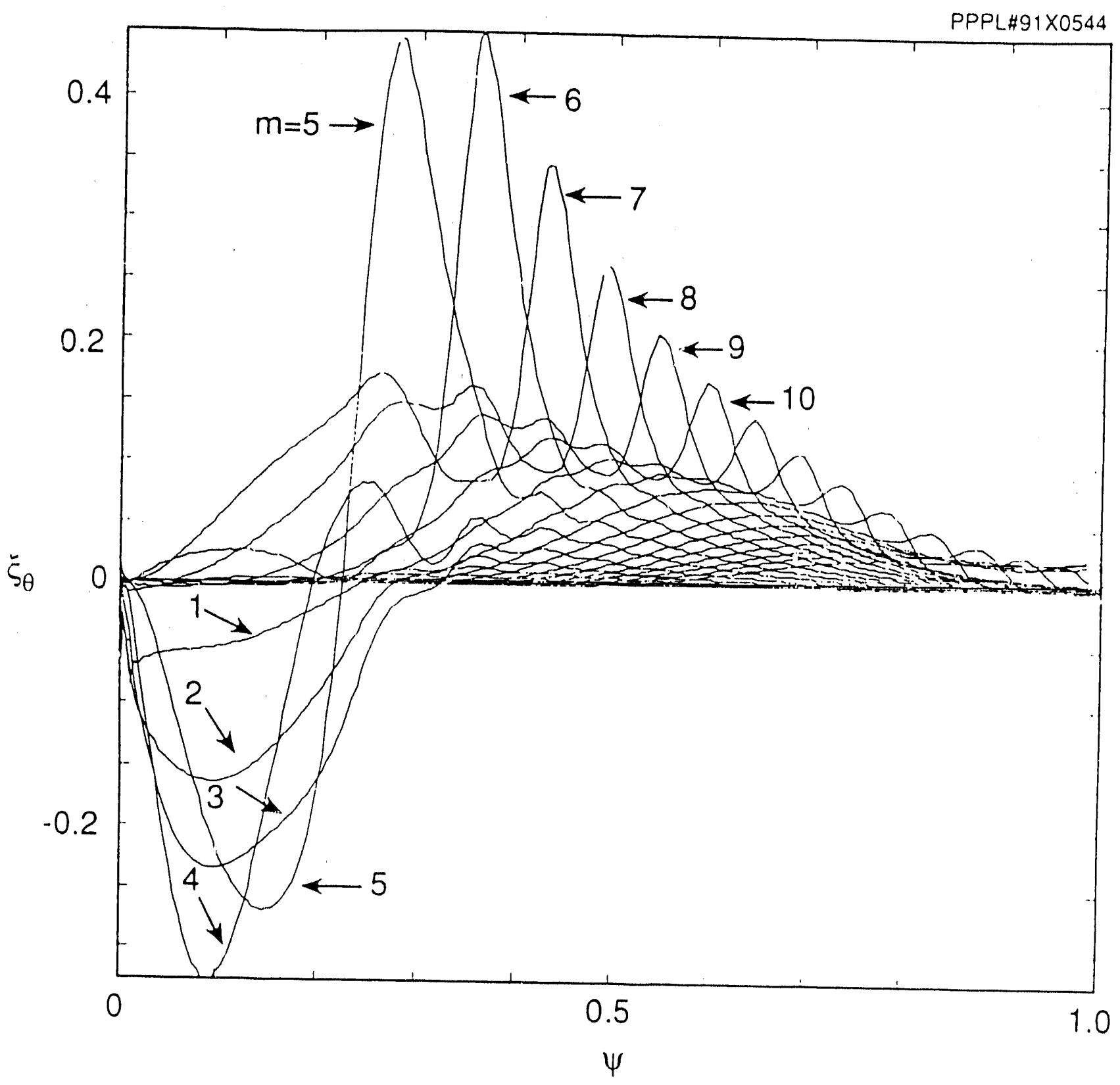

Fig. 16 


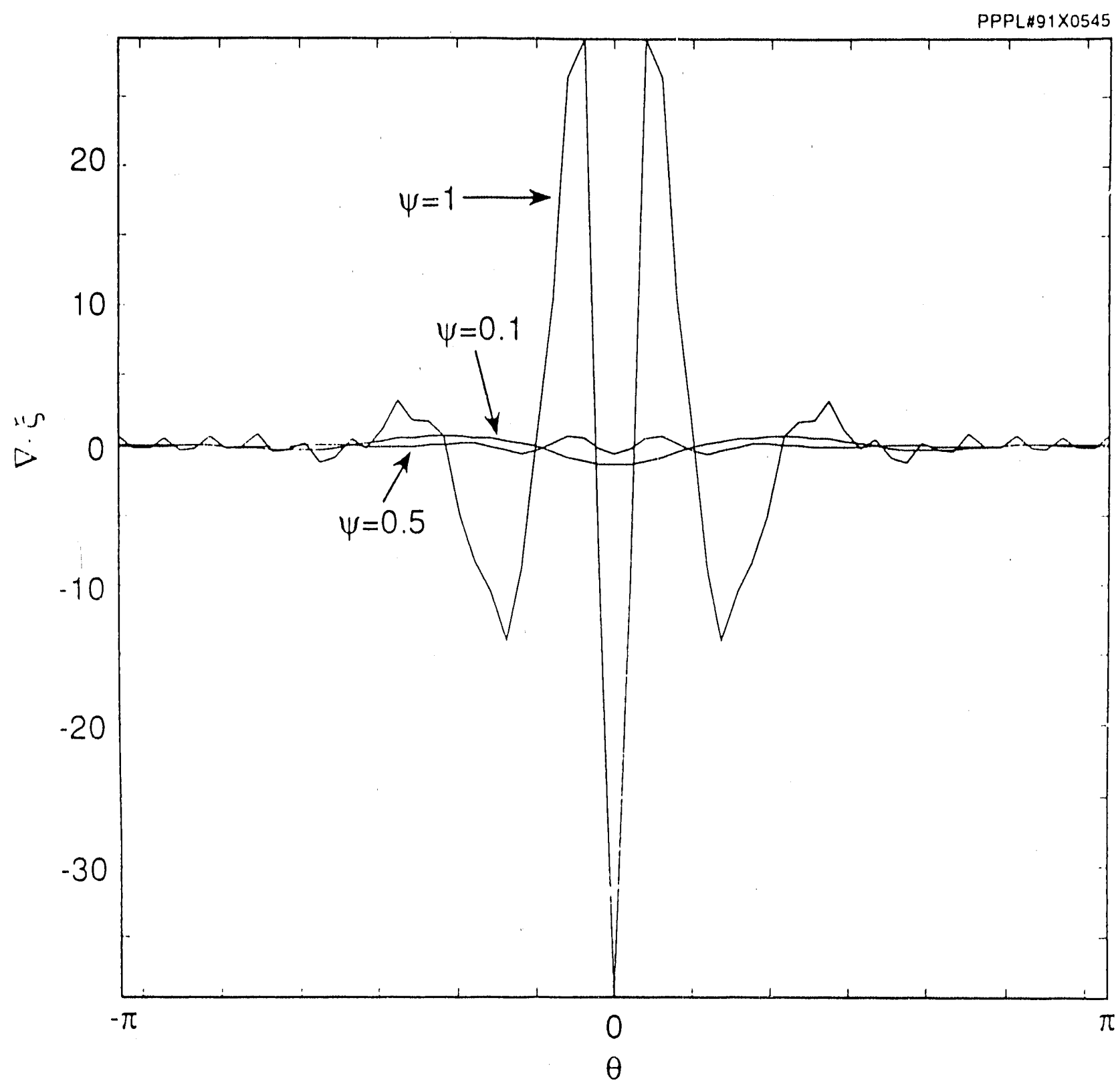

Fig. 17 


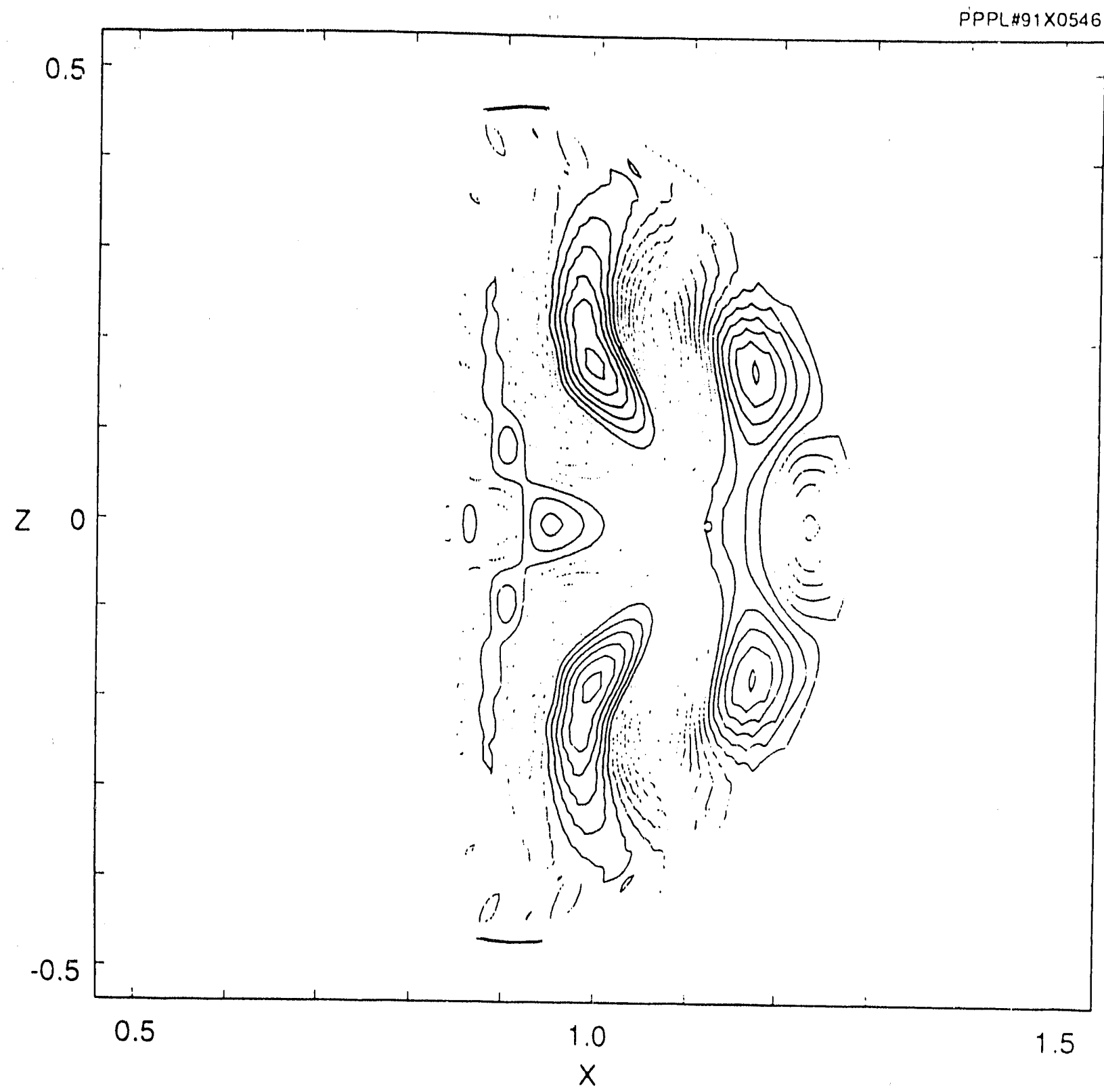

Fig. 18 


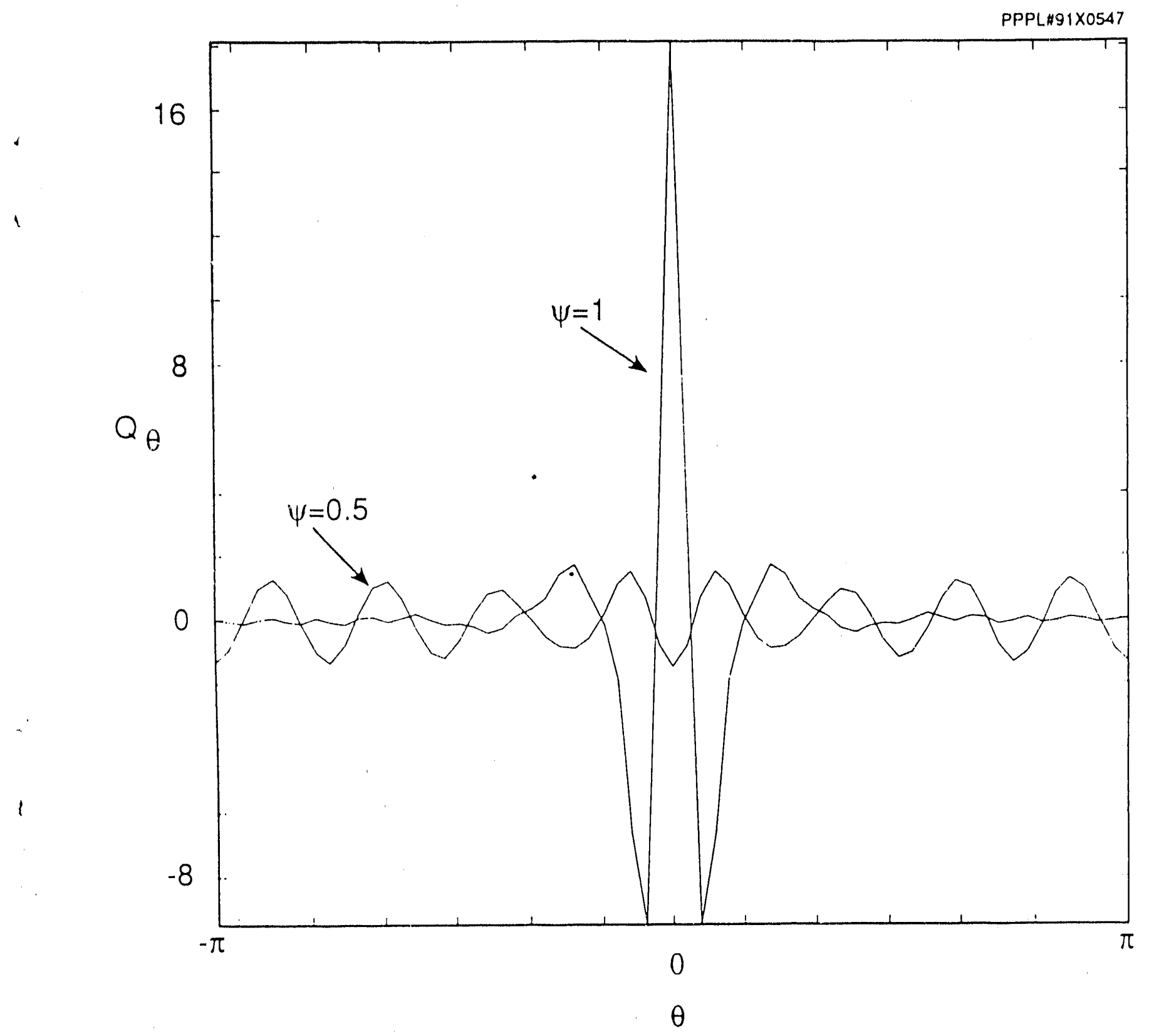

Fig. 19 


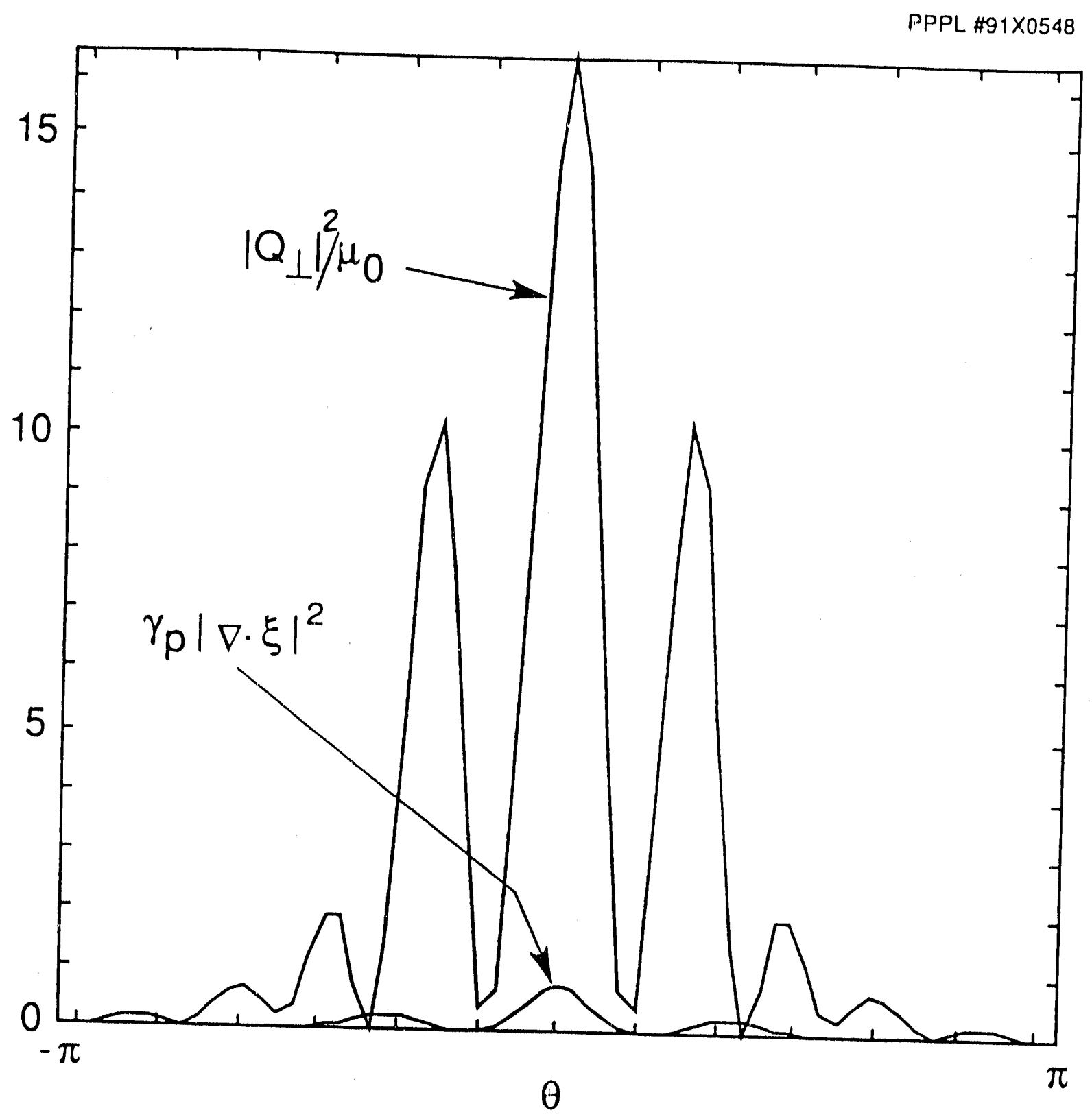

Fig. 20 
Dr. F. Paoloni, Univ. of Woltongong, AUSTRALIA

Prof. M.H. Brennen, Univ. of Sydney, AUSTRALIA

Plasma Reseanch Lab., Australian Nat. Univ., AUSTRALIA

Prof. I.R. Jones, Finders Univ, AUSTRALIA

Prof. F. Cap, Inst for Theoretical Physics, AUSTRIA

Prof. M. Heindter, Instiut fur Theoretisctio Physik, AUSTRIA

Prot. M. Gooseons, Astronomiech Insttuut, BELGIUM

Ecole Royde Militire, Lab. do Phy. Plasmas, BELGIUM

Commission-Europeen, DG. XII-Fusion Prog., BELGIUM

Prof. R. Bruciqus, Rijksuniveniteit Gent, BELGIUM

Dr. P.H. Sakanaka, Instituto Fhica, BRAZIL

Instituto Necional De Pesquieas Espaciaie-INPE, BRWZIL

Documents Office, Atomic Energy of Cenada Lid., CANADA

Dr. M.P. Bectynakd, MPB Technologies, Inc., CANADA

Dr. H.M. Skarsgand, Univ. of Sackatchewan, CANADA

Prof. J. Teichmann, Univ. of Montreal, CANADA

Prot. S.R. Sreenivacen, Univ. of Calgary, CANADA

Prof. T.W. Johnston, INRS-Energio, CANADA

Dr. A. Bolton, Contre canacien de fusion magnotique, CANADA

Dr. C.R. James, Univ. of Aberta, CANADA

Dr. P. Lukác, Komensketho Univorszita, CZECHO-SLOVAKIA

The LUbrarian, Culham Leboratory, ENGLAND

Librery, R61, Rutherford Appletion Laboratory, ENGLAND

Mrs. S.A. Hutchineon, JET Libran, ENGLAND

Dr. S.C. Sharma, Univ, of South Pacitic, FIJI ISLANDS

P. Mahonen, Univ. of Helsinid, FINLAND

Prof. M.N. Buseac, Ecole Polytochnique., FRANCE

C. Mouttert, Lab. de Physique des Milioux lonisés, FRANCE

J. Radal, CENMCADARACHE - Bat 506, FPANCE

Prot. E. Economou, Univ. of Crote, GREECE

Ms. C. Rinni, Uniw. of loamina, GREECE

Dr. T. Mud, Academy Bbilographic Ser., HONG KONG

Preprint Library, Hungarian Acadomy of Sci., HUNGARY

Dr. B. DasGupta, Saha Inst. of Nuctear Physics, INDIA

Dr. P. Kaw, Inst. for Plasma Rosearch, INDIA

Dr. P. Rosenau, leraed Inst of Technology, ISPAEL

Librarian, Intemational Contor for Theo Physics, ITALY

Miss C. De Palo, Associaziono EURATOM-ENEA, ITALY

Dr. G. Grosso, Istitubo di Fisica del Plasma, ITALY

Prof. G. Rostengni, letituto Gas lonizzati Dol Cnr, ITALY

Dr. H. Yamato, Tochiba Pes a Dovol Conter, JAPAN
Prof. I. Kawakami, Hiroshima Univ., JAPAN

Prof. K. Nishikawa, Hiroshima Univ., JAPAN

Director, Japen Atomic tinergy Research Inst., JAPAN

Prof. S. 10h, Kyushu Univ.. JAPAN

Research info. Ctr., National instit. for Fusion Science, JAPAN

Prot. S. Tenaka, Kyob Univ., JAPAN

Library, Kyoto Univ., JAPAN

Prof. N. Inow, Univ. of Tokyo, JAPAN

Secrotary, Plasma Section, Electrotochnical Lab., JAPAN

S. Mori, Tectrinical Adwicor, LAERI, LAPAN

Dr. O. Miterai, Kumamow Inst. of Technology, JAPAN

J. Hycon-Sook, Korea Alomic Eneroy Research inst, KOREA

D.I. Chod, The Korea Aov. Inet. of Sd. \& Tech., KOREA

Prof. B.S. Lloy, Univ. of Waikaro, NEW ZEALAND

Inst of Physica, Chinese Acad SCt PEOPLE'S REP. OF CHINA

Library, Inst of Plasma Physics, PEOPLE'S REP. OF CHINA

Tsinghua Univ. Lbrary, PEOPLE'S REPUBLIC OF CHINA

Z. U. S.W. Inat Physica, PEOPLE'S REPUBUC OF CHINA

Prof. J.A.C. Cabre, Instituto Superior Tecnico, PORTUGAL

Dr. O. Potrue, Al I CUzA Univ., RomanIA

Di. J. de Villiers, Fueion Studies, AEC, S. AFRICA

Prof. M.A. Hellbero, Univ. of Natal, S. AFRICA

Prof. D.E. Km, Pohang Inet. of Sci. \& Tech., SO. KOREA

Prof. C.I.E.M.A.T, Fusion Division Library, SPAIN

Dr. L. Stontio, Univ. of UMEA, SWEDEN

Library, Royal Inst. of Tectnology, SWEDEN

Prot. H. Withelmson, Chaimers Univ, of Tech., SWEDEN

Centre Phys. Des Plaemas, Ecole Polytech, SWITZERLAND

Bibliothoek, Inst. Voor Plasma-Fysics, THE NETHERLANDS

Asst. Prot. Dr. S. Cakir, Middo East Tech. Univ., TURKEY

Dr. V.A. Gukhikh, Sol. Res. Inst Electrophys.I Apparatus, USSR

D. D.D. Ayulov, Siberian Branch of Acadomy of Sa., USSR

Dr. G.A. Eliseov, I.V. Kurchatov Inst, USSR

Librarian, The Ukr.SSR Academy of Scionces, USSR

Dr. LM. Kovizinmykh, Inst. of General Physics, USSR

Kemforschungsaniage GmbH, Zentrablbibliothek, W. GERMANY

Bibliothek, Inst. For Plasmatorschung, W. GERMANY

Prof. K. Schindler, Ruhr-Universitat Bochum, W. GERMANY

Dr. F. Wogner, (ASDEX), Max-Planck-Institut, W. GERMANY

Librarien, Max-Planck-Instiut, W. GERMANY

Prol. R.K. Janov, Inst. of Physics, YUgOSLAVIA 
7
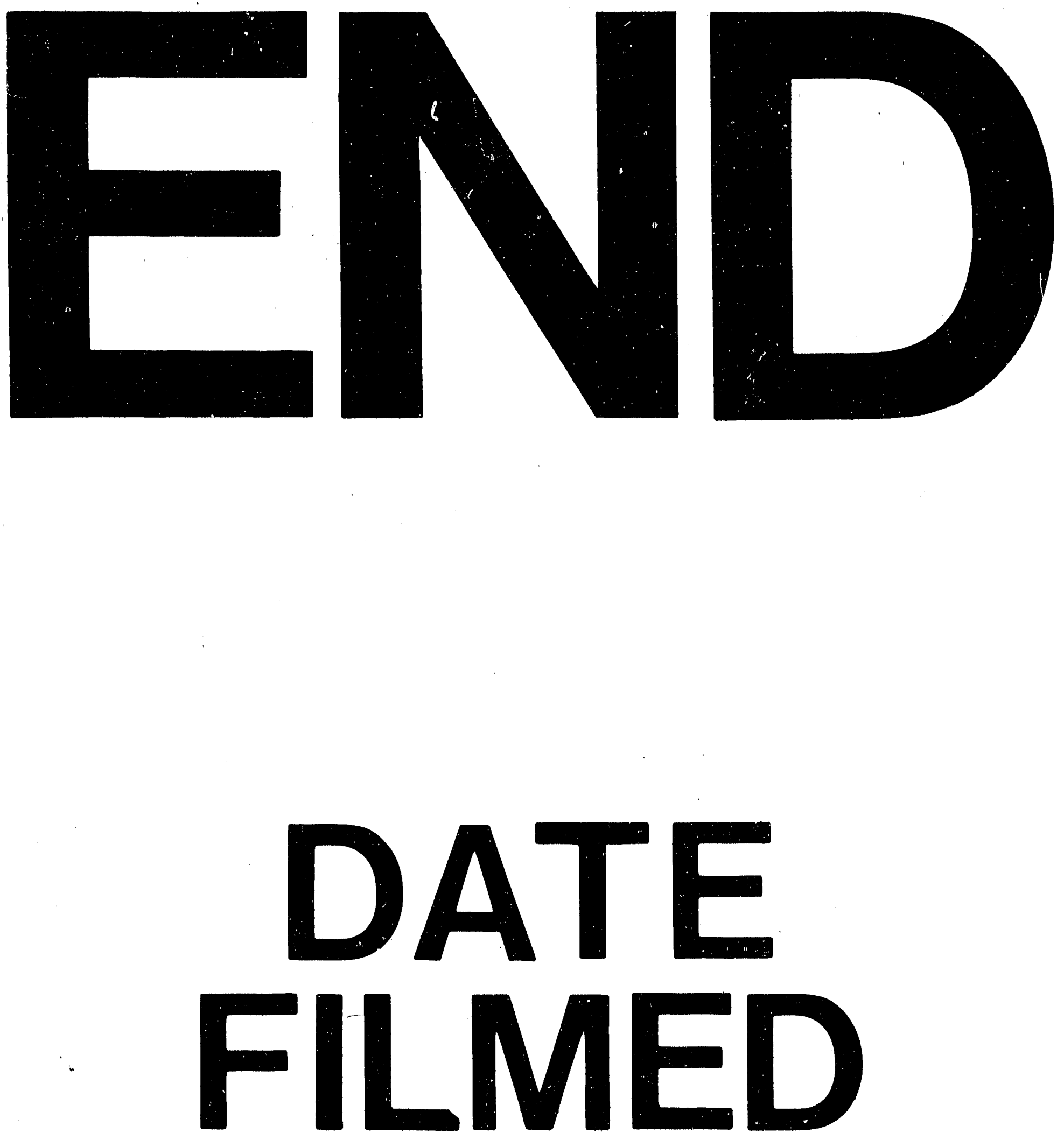

I

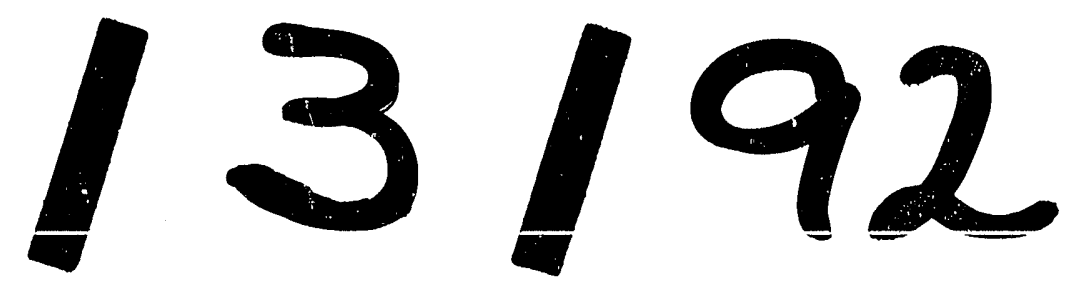


